\title{
New Class of Supramolecular Bowl-Shaped Columnar Mesogens Derived from Thiacalix[4]arene Exhibiting Gelation and Organic Light-Emitting Diodes Applications
}

Vinay S.Sharma ${ }^{a^{*}}$, Anuj S.Sharma ${ }^{b}$, Akshara P.Shah ${ }^{c}$, Priyanka A.Shah ${ }^{b}$, Pranav

S.Shrivastav ${ }^{b}$, Mohd Athar

$a^{*}$ : Department of Chemistry, Faculty of Basic and Applied Sciences, Madhav University, Abu road, Sirohi, Rajasthan.

b: Department of Chemistry, School of Science, Gujarat University, Ahmedabad, Gujarat.

C. Department of Chemistry, Mumbai University, Santacruz, Mumbai.

: Department of Chemistry, Central University of Gujarat, Ghandhinagar, India.

Email address of corresponding author ${ }^{\mathrm{a}}$ : vinaysharma3836@gmail.com

Contents:

1. TGA, DSC data...................................................................

2. POM data......................................................................

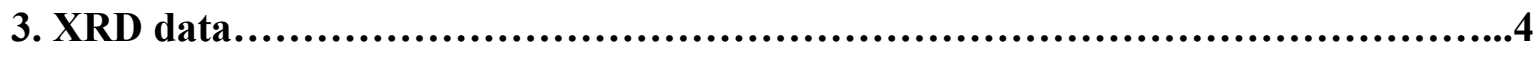

4. UV, fluorescence data.................................................................5

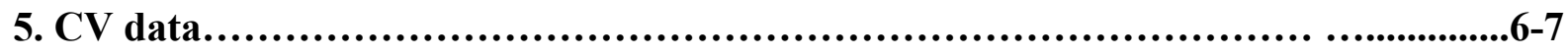

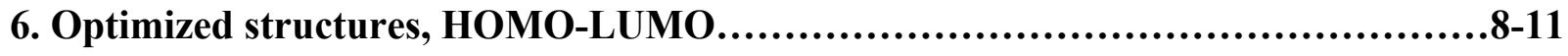

7. Gelation data.....................................................................11

8. Electroluminescence data......................................................... 18

8. ${ }^{1} \mathrm{H}$ NMR, ${ }^{13} \mathrm{C}$ NMR and ESI-Mass............................................... 19-42

9. References...............................................................................43 


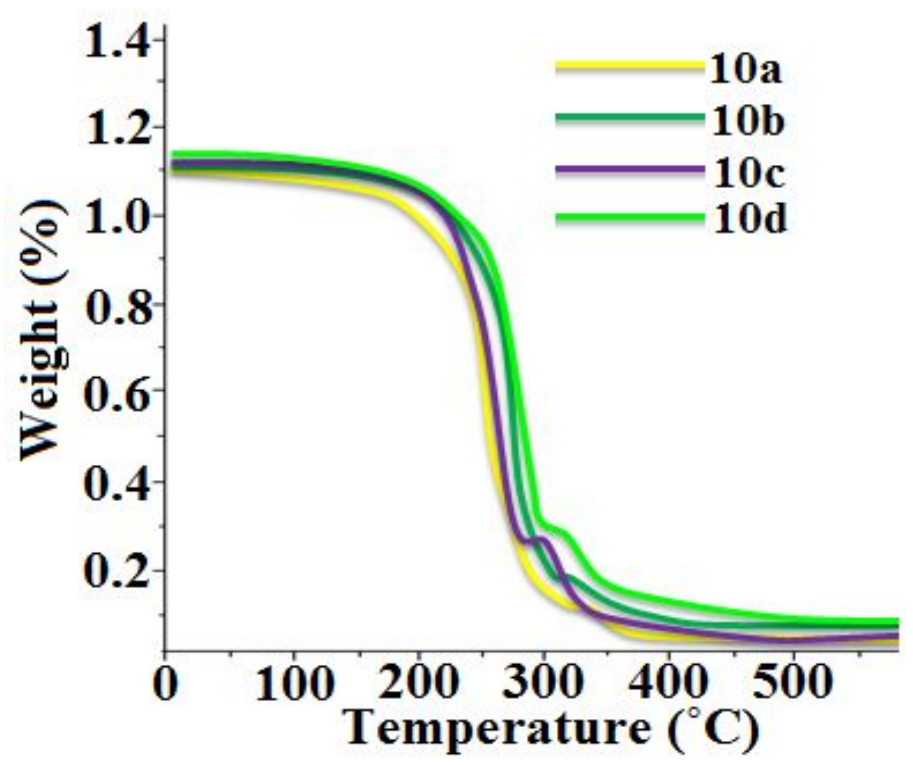

Figure S1. TGA curves of the compounds $10 a-10 d$ carried out at a rate of $10^{\circ} \mathrm{C} / \mathrm{min}$.
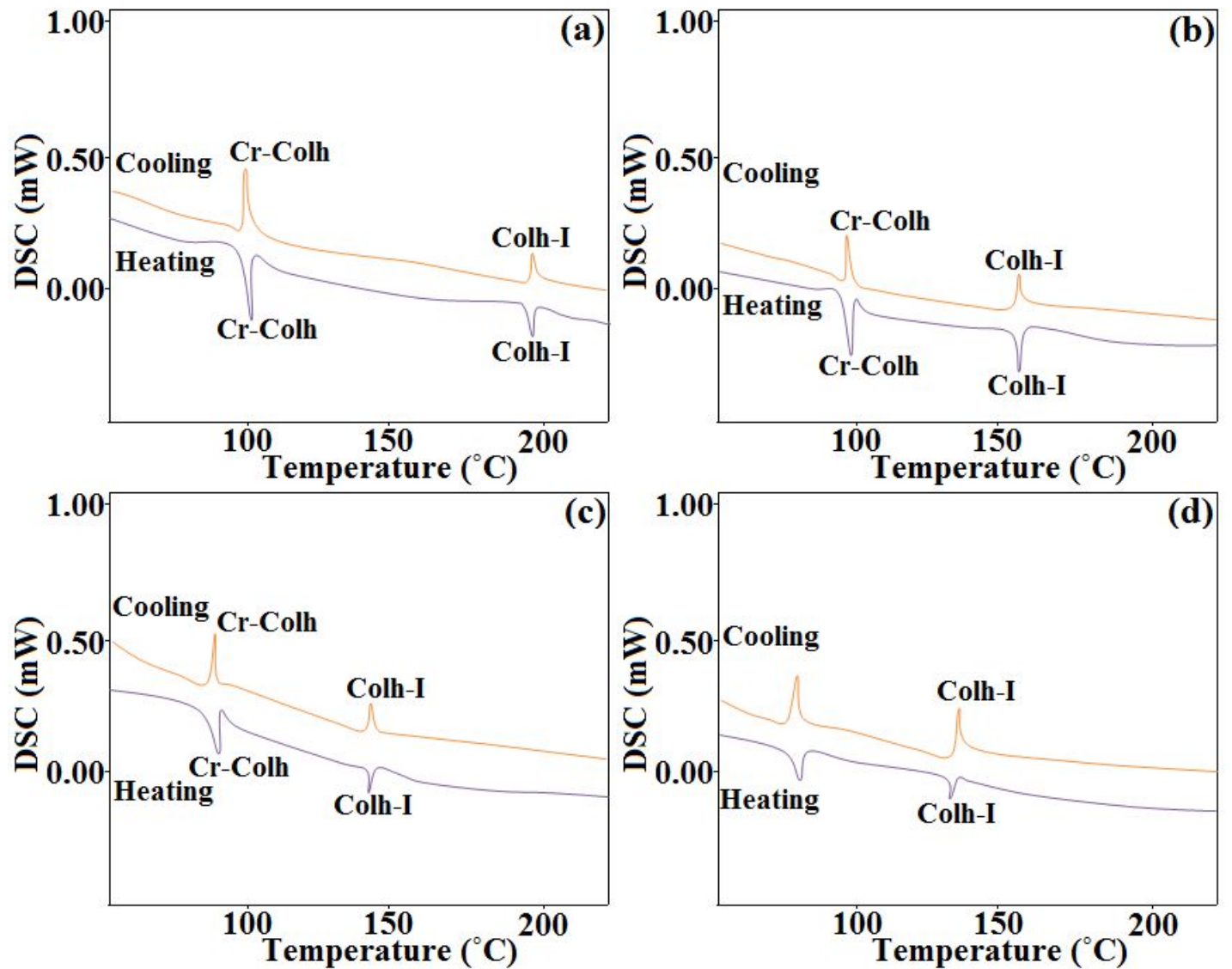

Figure S2. The DSC traces of compounds 10a (a), 10b (b), 10c (c) and 10d (d) on first heating and cooling ( $\operatorname{scan}$ rate $\left.10^{\circ} \mathrm{C} / \mathrm{min}\right)$. 


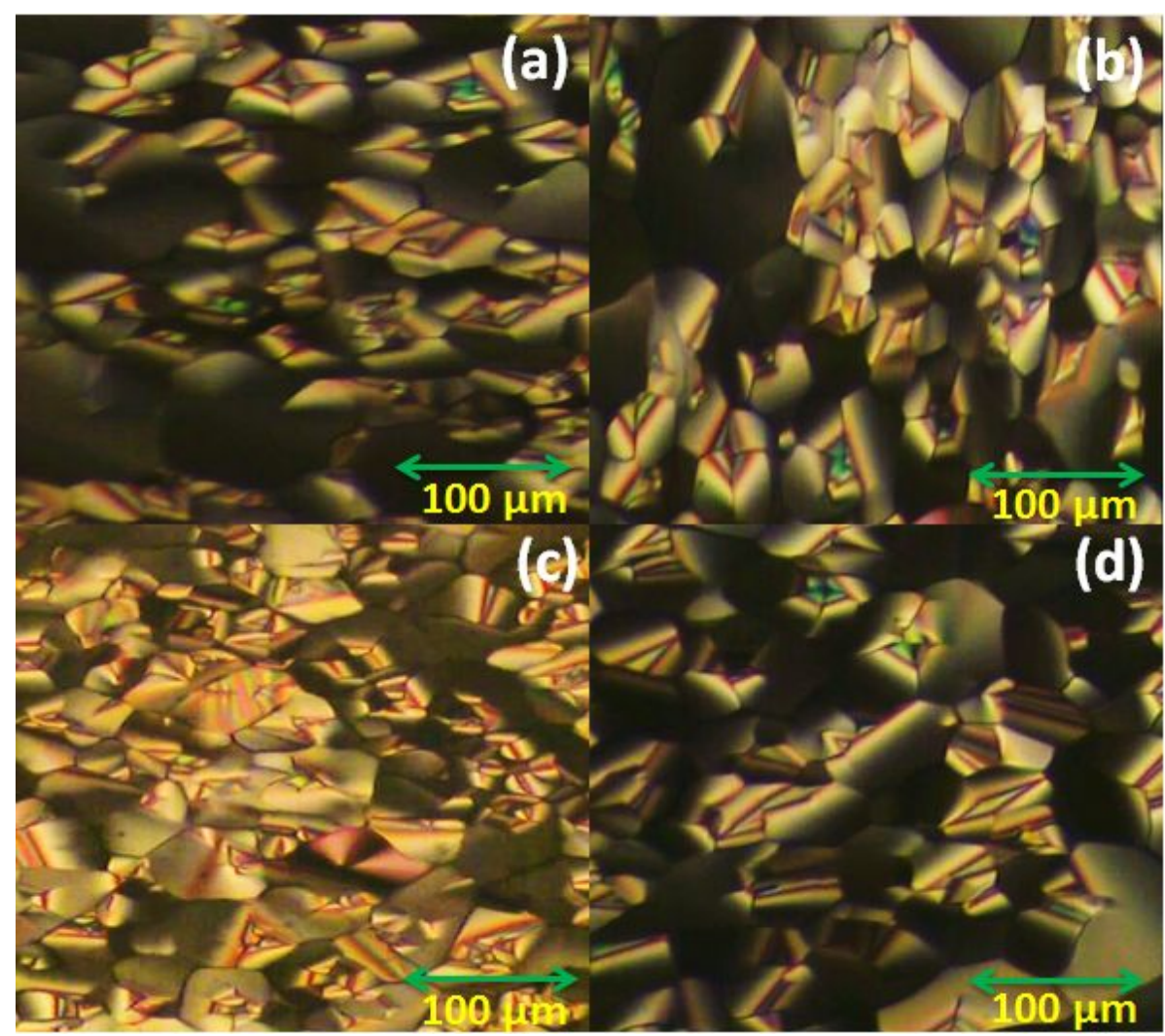

Figure S3. POM texture image of compound $10 \mathrm{a}$ at $102.8{ }^{\circ} \mathrm{C}$ (a) compound $10 \mathrm{~b}$ at $94.8^{\circ} \mathrm{C}$ (b) compound 10c at $75.2{ }^{\circ} \mathrm{C}(\mathrm{c})$ and compound $10 \mathrm{~d}$ at $61.6{ }^{\circ} \mathrm{C}$ (d) on heating condition from solid crystalline state as seen under cross polarizers. 

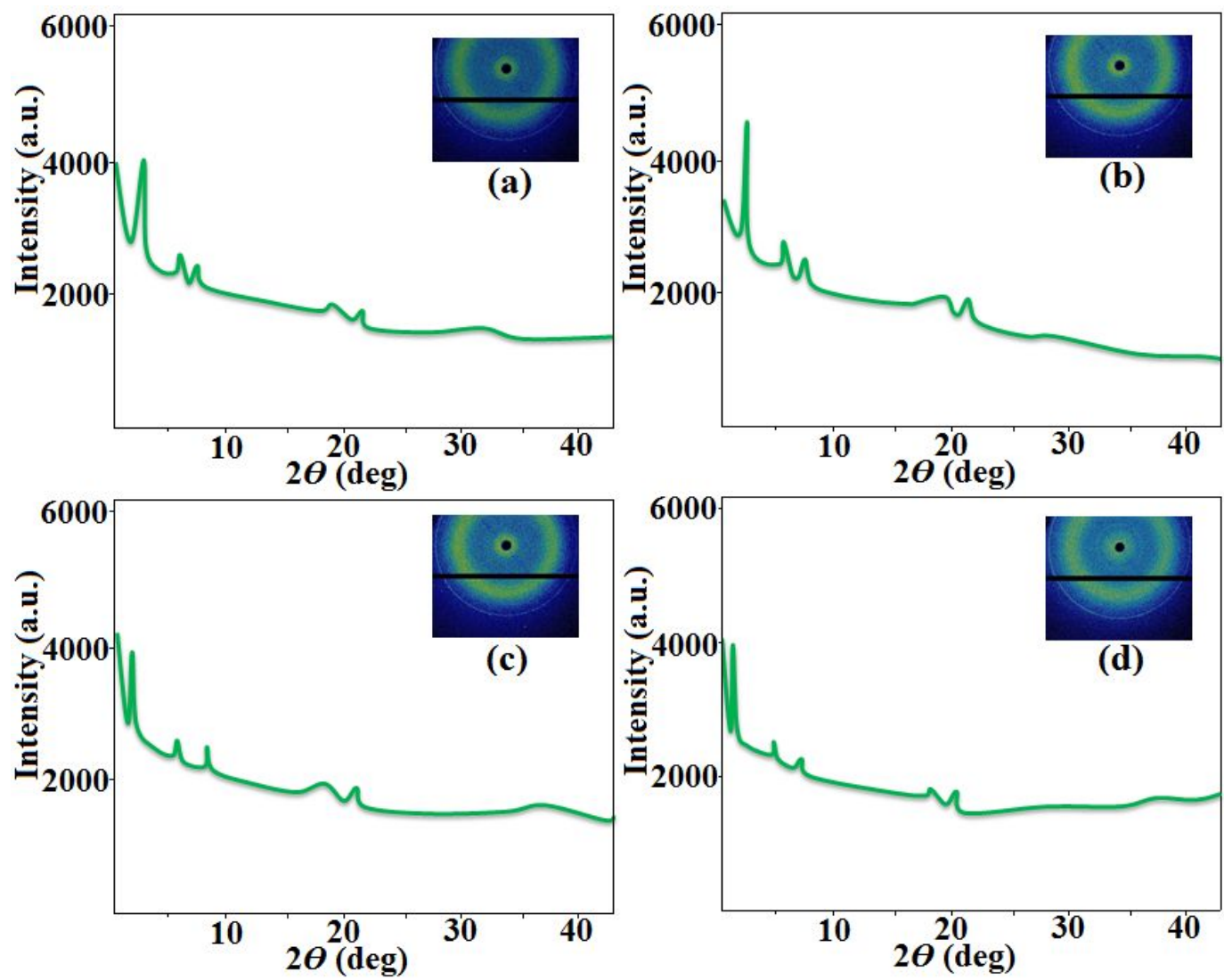

Figure S4. XRD profiles depicting the intensity against the $2 \theta$ obtained for the $\mathrm{Col}_{\mathrm{h}}$ phase of compound 10a at $104.0{ }^{\circ} \mathrm{C} \mathrm{(a);} \mathrm{Col}_{\mathrm{h}}$ phase of compound $10 \mathrm{~b}$ at $94.0{ }^{\circ} \mathrm{C}(\mathrm{b}) ; \mathrm{Col}_{\mathrm{h}}$ phase of compound $10 \mathrm{c}$ at $78.0{ }^{\circ} \mathrm{C}(\mathrm{c}) ; \mathrm{Col}_{\mathrm{h}}$ phase of compound $10 \mathrm{~d}$ at $66.0^{\circ} \mathrm{C}$ (d) on cooling from isotropic temperature; the insert shows the image pattern obtained. 

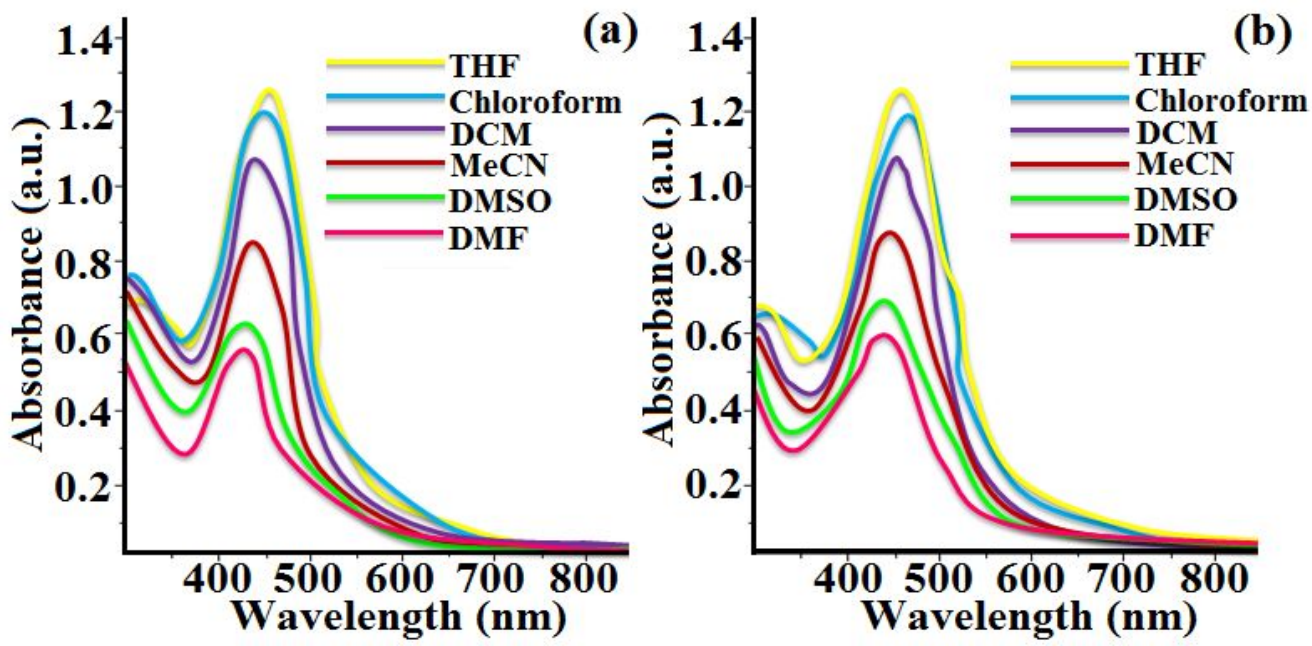

Figure S5. Absorption spectra of compound 10a (a); compound 10d (b) in different solvents $(0.05 \mu \mathrm{M})$.

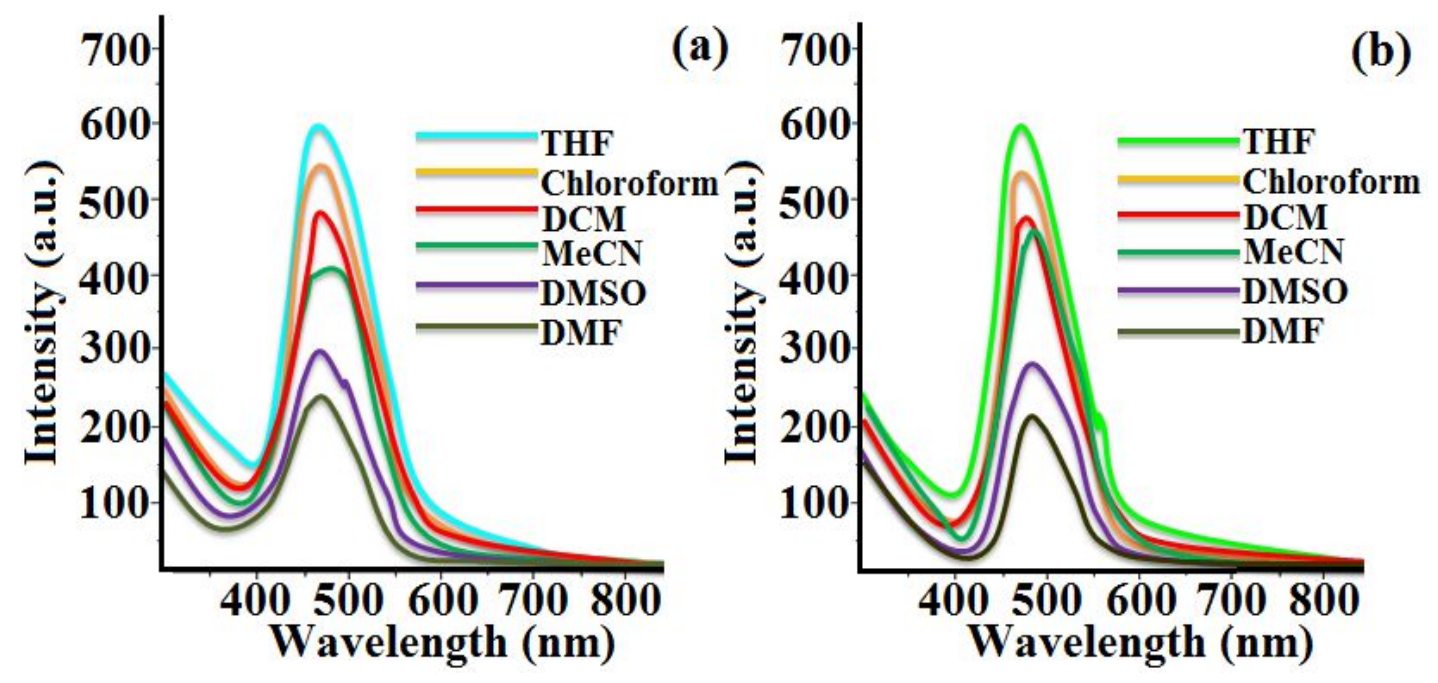

Figure S6. Fluorescence spectra of compound 10a (a); compound 10d (b) in different solvents $(0.05 \mu \mathrm{M})$. 


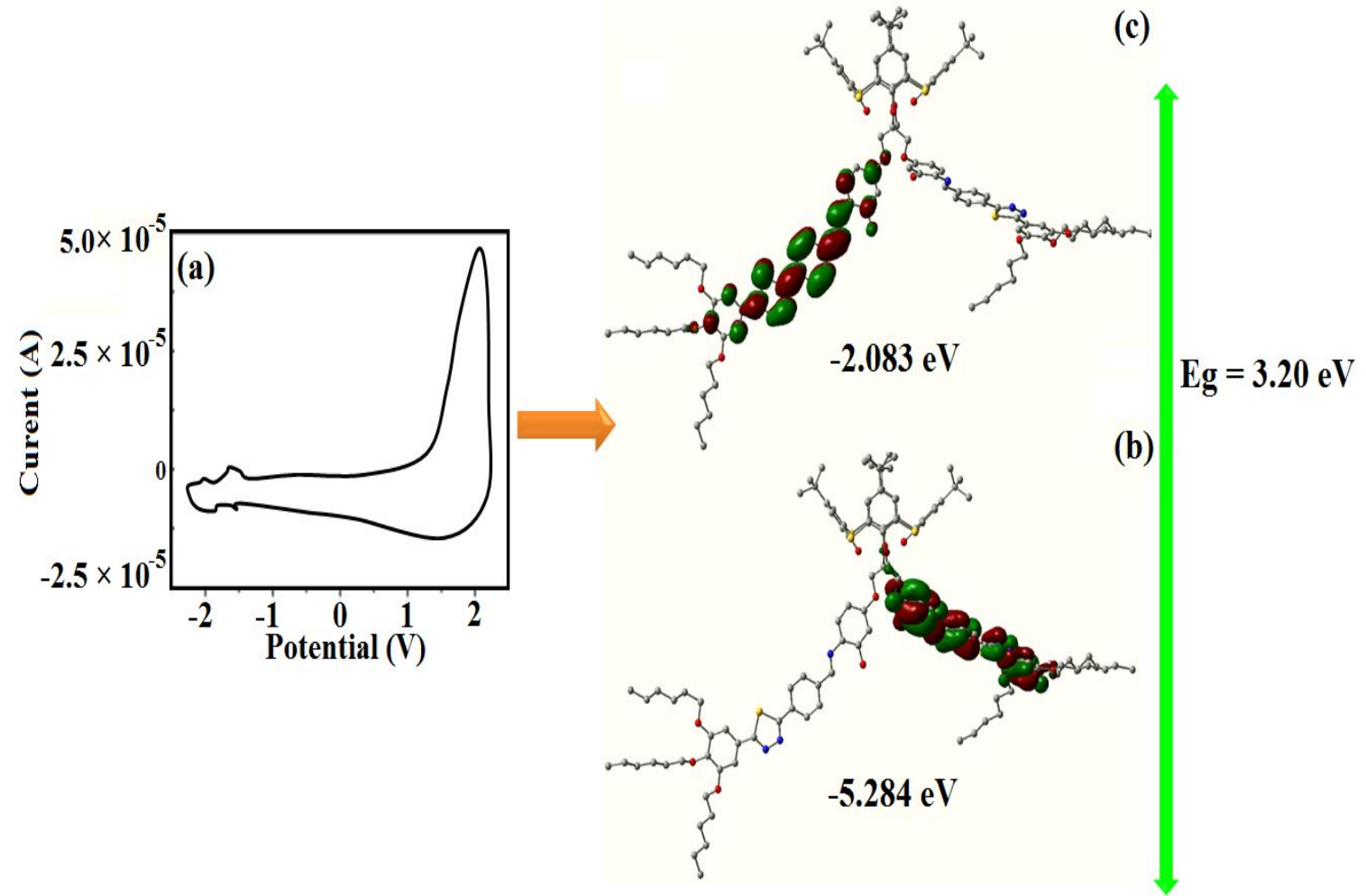

Figure S7. (a) Cyclic voltammogram of compound 10b in anhydrous THF solution of TBAP $(0.1 \mathrm{M})$ at a scanning rate of $0.5 \mathrm{mV} / \mathrm{s}$. (b,c) The HOMO and LUMO levels of compound $\mathbf{1 0 b}$ obtained from DFT calculation at the B3LYP/3-21G*level using Gaussian 09. Hydrogen atoms were omitted for clarity.

Table $\mathbf{S}_{\mathbf{1}}$. Electrochemical properties of compounds 10a-10d

\begin{tabular}{|c|c|c|c|c|c|}
\hline Comp. & Eoxd & Ered & $\mathbf{E}_{\text {Hомо }}$ & $\mathbf{E}_{\text {LUmo }}$ & $\Delta \mathbf{E}_{\mathbf{g}}, \mathbf{C V}$ \\
\hline $\mathbf{1 0 a}$ & 1.59 & -1.52 & -5.82 & -2.71 & 3.11 \\
\hline $\mathbf{1 0 b}$ & 1.57 & -1.50 & -5.80 & -2.72 & 3.08 \\
\hline $\mathbf{1 0 c}$ & 1.58 & -1.49 & -5.81 & -2.74 & 3.07 \\
\hline $\mathbf{1 0 d}$ & 1.61 & -1.54 & -5.85 & -2.69 & 3.16 \\
\hline
\end{tabular}

Experimental conditions: $\mathrm{Ag} / \mathrm{AgNO} 3$ as a reference electrode, platinum wire as counter electrode, glassy carbon as working electrode, tetrabutylammonium perchlorate $(0.1 \mathrm{M})$ as supporting electrolyte, room temperature 


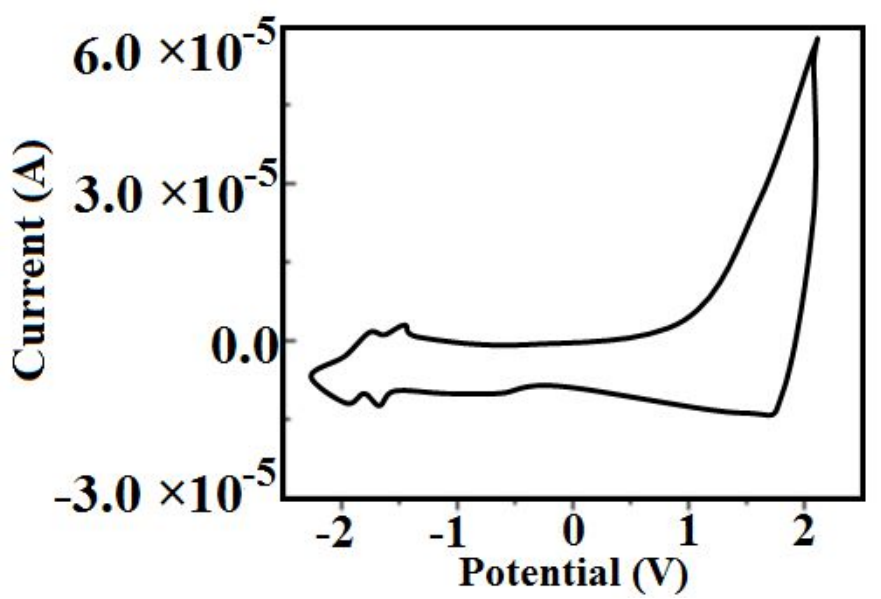

Figure S8. Cyclic voltammogram of compound 10c in anhydrous THF solution of TBAP $(0.1$ $\mathrm{M})$ at a scanning rate of $0.5 \mathrm{mV} / \mathrm{s}$.

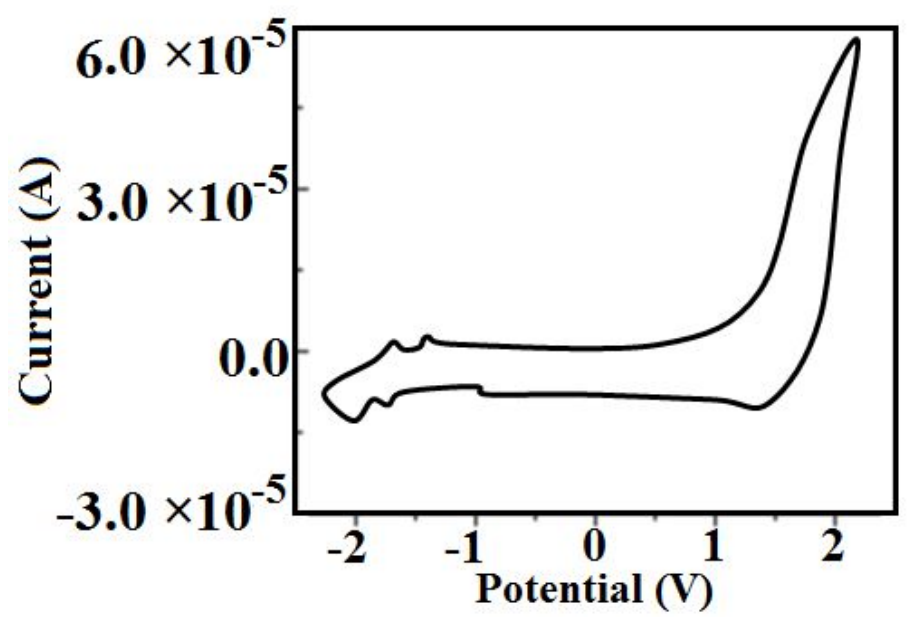

Figure S9. Cyclic voltammogram of compound 10d in anhydrous THF solution of TBAP $(0.1$ $\mathrm{M})$ at a scanning rate of $0.5 \mathrm{mV} / \mathrm{s}$. 


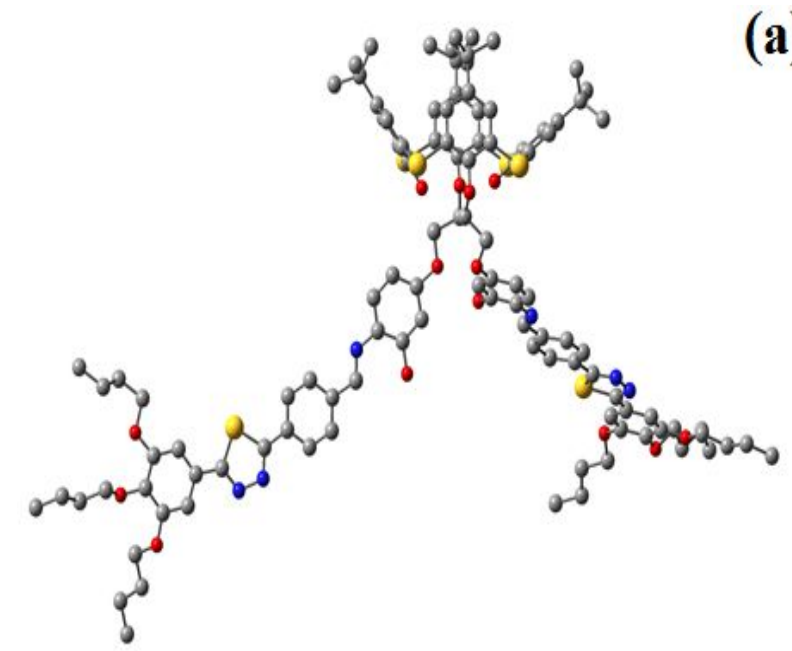

(a)

(b)

Figure S10. Optimized geometries of 1,3,4-thiadiazole based thiacalix[4]arene derivatives (a) 10a (cone conformation); (b) 10b (cone conformation) at B3LYP/3-21G level. Hydrogens were omitted for clarity.

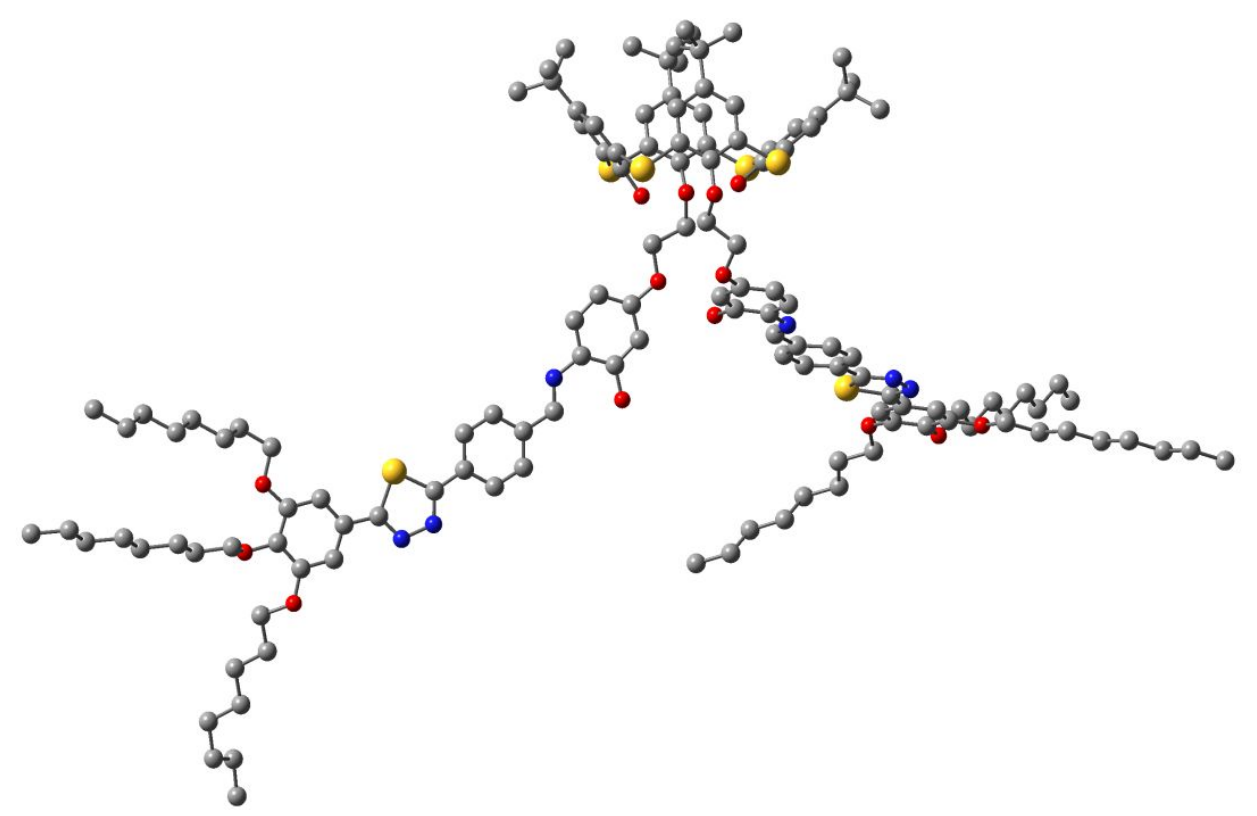

Figure S11. Optimized geometries of 1,3,4-thiadiazole based thiacalix[4]arene derivatives 10c (cone conformation) at B3LYP/3-21G level. Hydrogens were omitted for clarity. 


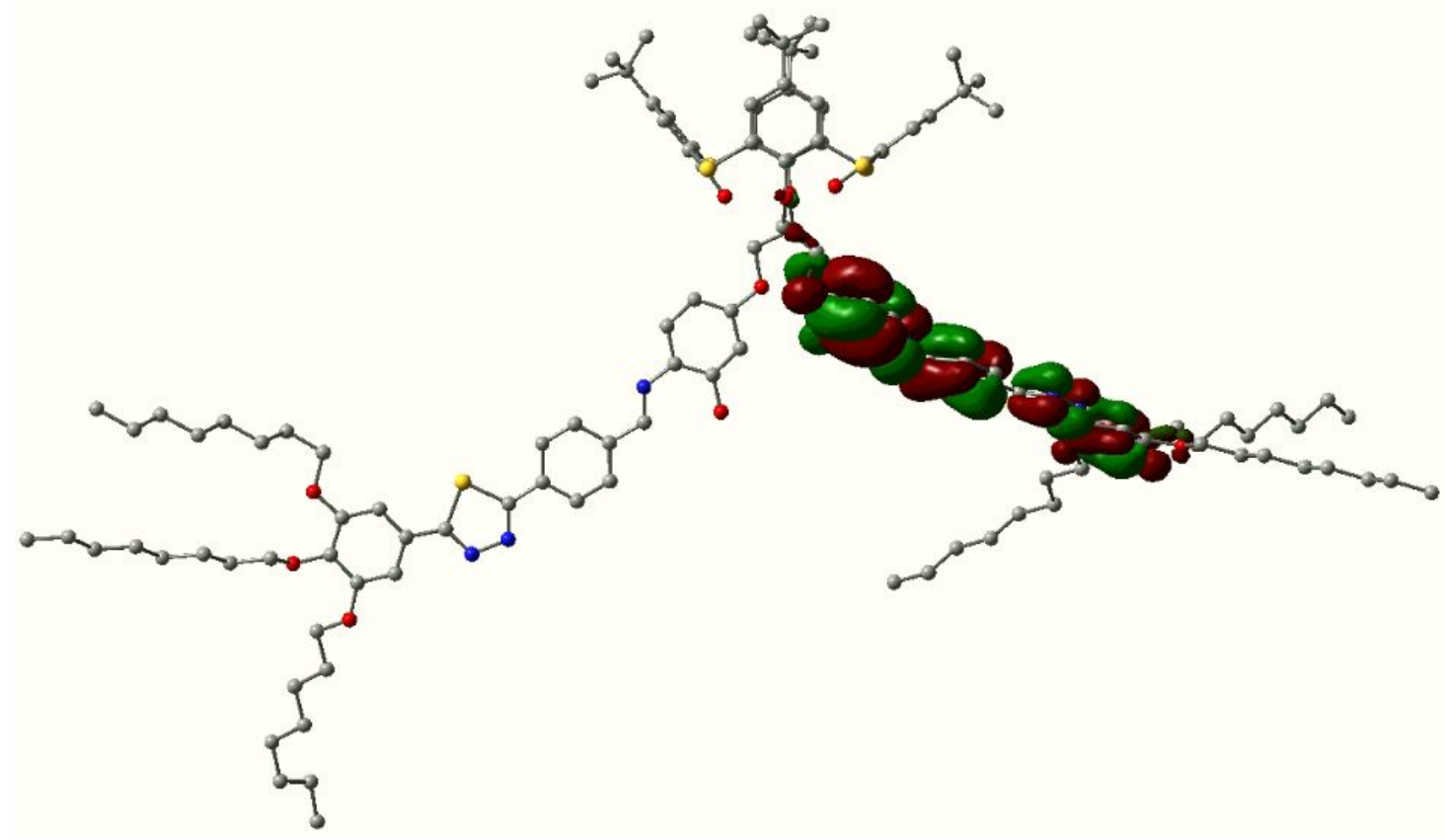

Figure S12. The HOMO energy levels of compound 10c obtained from DFT calculation at the B3LYP/3-21G* level. Hydrogen atoms were omitted for clarity.

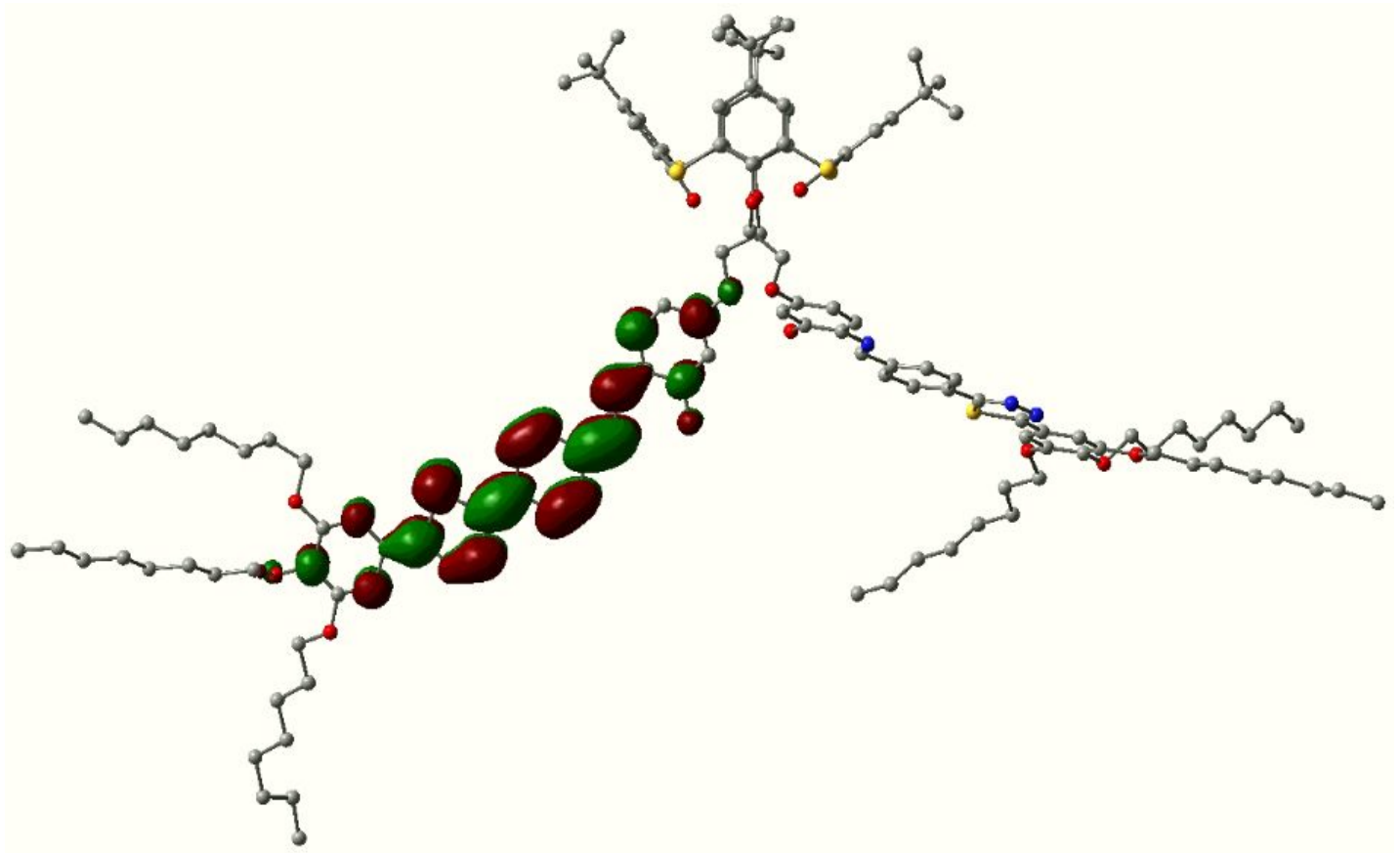

Figure S13. The LUMO energy levels of compound 10c obtained from DFT calculation at the B3LYP/3-21G* level. Hydrogen atoms were omitted for clarity. 


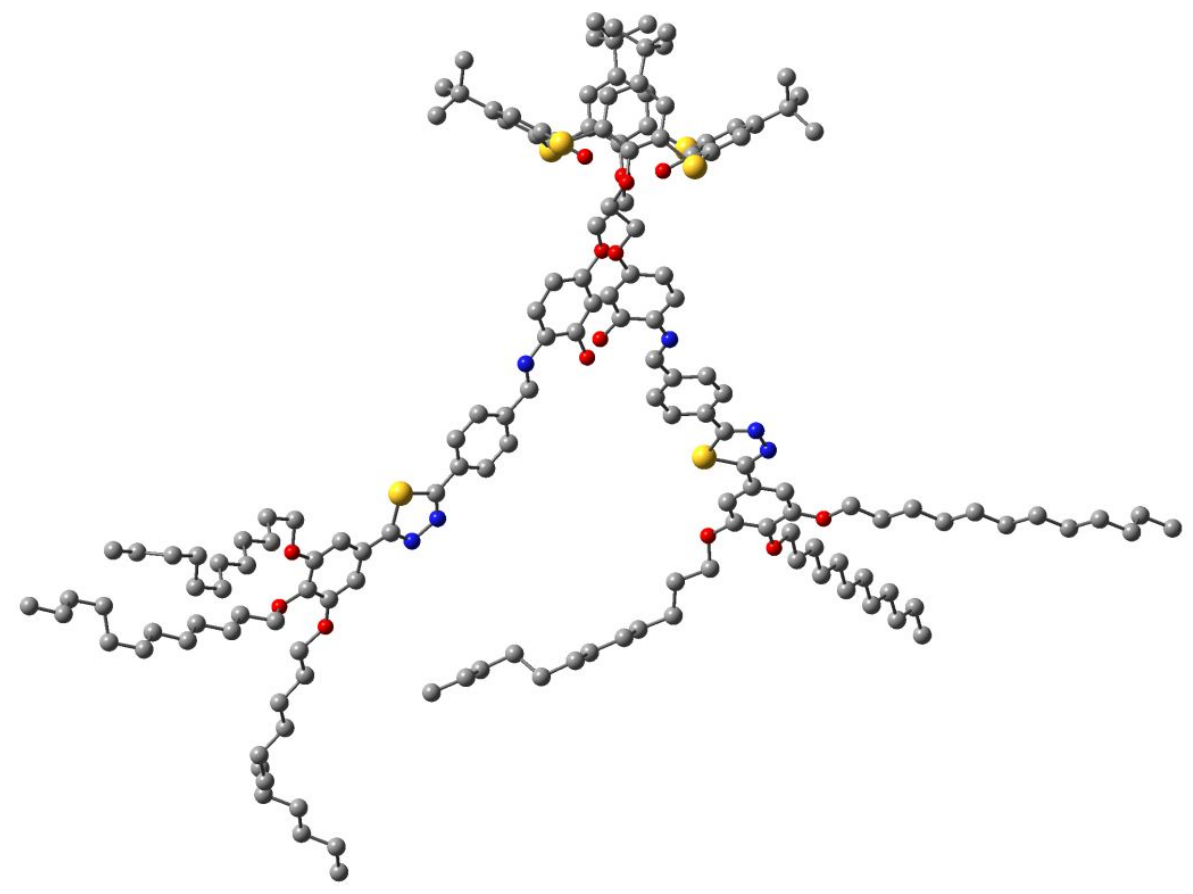

Figure S14. Optimized geometries of 1,3,4-thiadiazole based thiacalix[4]arene derivatives 10d (cone conformation) at B3LYP/3-21G level. Hydrogens were omitted for clarity.

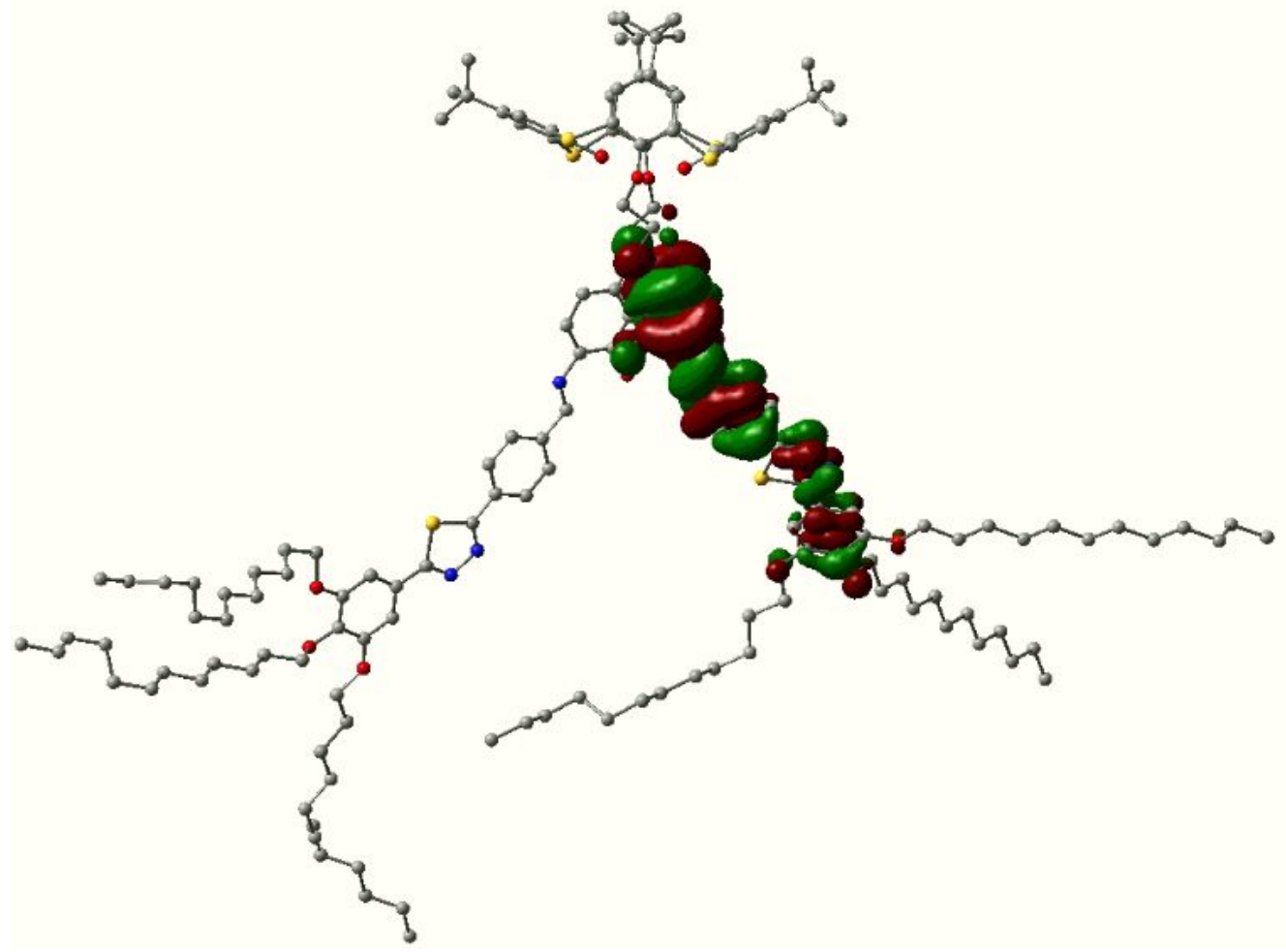

Figure S15. The HOMO energy levels of compound 10d obtained from DFT calculation at the B3LYP/3-21G* level. Hydrogen atoms were omitted for clarity. 


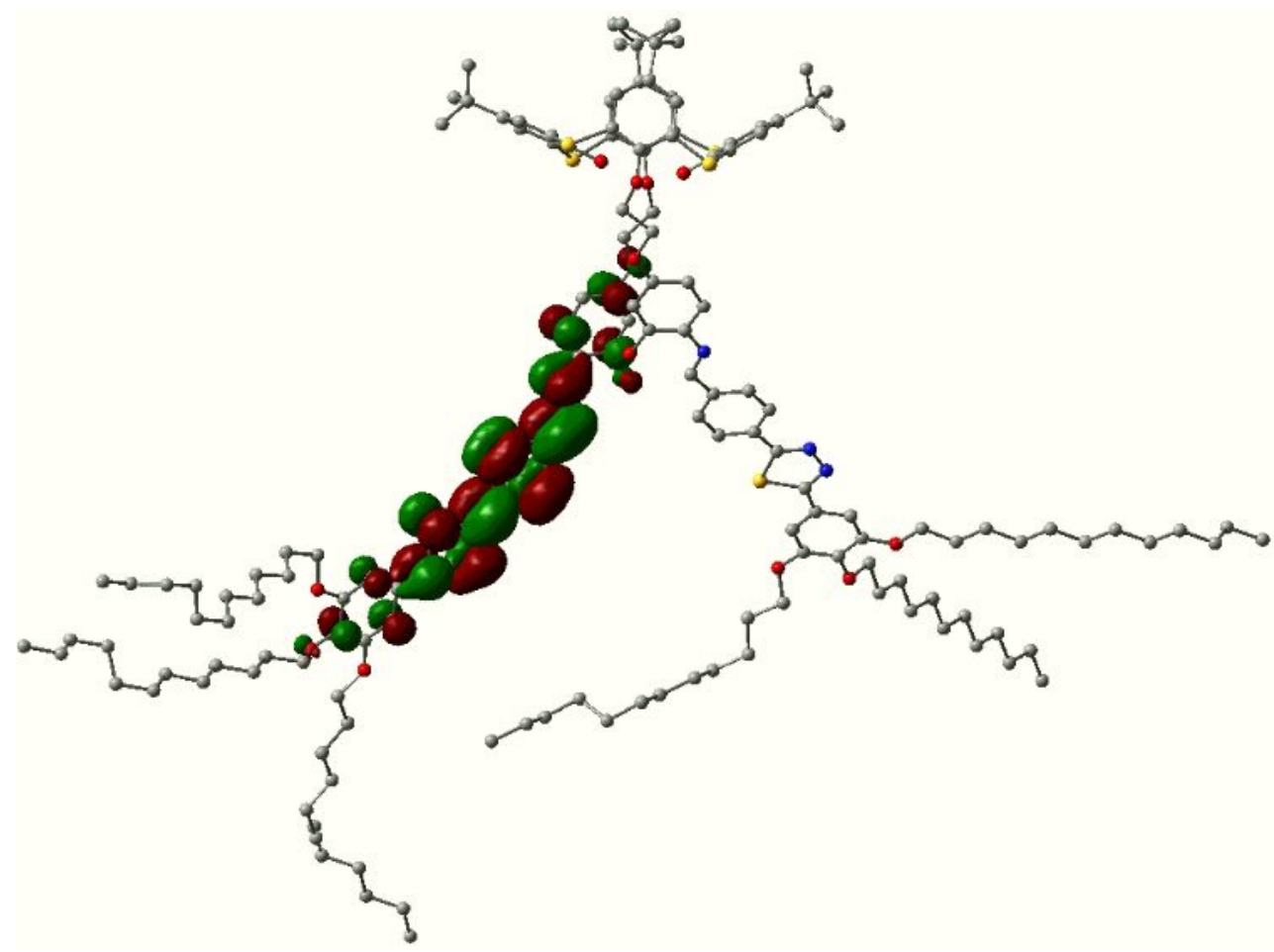

Figure S16. The LUMO energy levels of compound 10d obtained from DFT calculation at the B3LYP/3-21G* level. Hydrogen atoms were omitted for clarity.

Table $\mathbf{S}_{2}$. Gelation behaviour of compound $10 \mathrm{c}$ and $\mathbf{1 0 d}$

\begin{tabular}{|c|c|c|c|c|c|}
\hline \multirow[t]{2}{*}{ Sr.No. } & \multirow[t]{2}{*}{ Solvent } & \multicolumn{2}{|c|}{ Comp.10c } & \multicolumn{2}{|c|}{ Comp.10d } \\
\hline & & Properties & $\begin{array}{c}\text { CGC } \\
(w t \%)\end{array}$ & Properties & $\begin{array}{c}\text { CGC } \\
(w t \%)\end{array}$ \\
\hline 1 & Decane & $\mathrm{G}(\mathrm{O})$ & $1.6 \mathrm{wt} \%$ & $\mathrm{G}(\mathrm{O})$ & $1.9 \mathrm{wt} \%$ \\
\hline 2 & Dodecane & $\mathrm{G}(\mathrm{O})$ & $1.1 \mathrm{wt} \%$ & $\mathrm{G}(\mathrm{O})$ & $1.5 \mathrm{wt} \%$ \\
\hline 3 & Toluene & $\mathrm{S}$ & - & $\mathrm{S}$ & - \\
\hline 4 & Benzene & $\mathrm{S}$ & - & $\mathrm{S}$ & - \\
\hline 5 & $\mathrm{DCM}$ & $\mathrm{S}$ & - & $\mathrm{S}$ & - \\
\hline
\end{tabular}




\begin{tabular}{|c|c|c|c|c|c|}
\hline 6 & THF & S & - & S & - \\
\hline 7 & Chloroform & S & - & S & - \\
\hline 8 & Ethanol & P & - & P & - \\
\hline 9 & Butanol & P & - & P & - \\
\hline 10 & Methanol & P & - & P & - \\
\hline
\end{tabular}

$\mathrm{G}=$ stable gel; $\mathrm{P}=$ precipitate; $\mathrm{O}=$ opaque; $\mathrm{S}=$ the critical gelation concentration (wt $\%$ ) is the minimum concentration necessary for gelation.

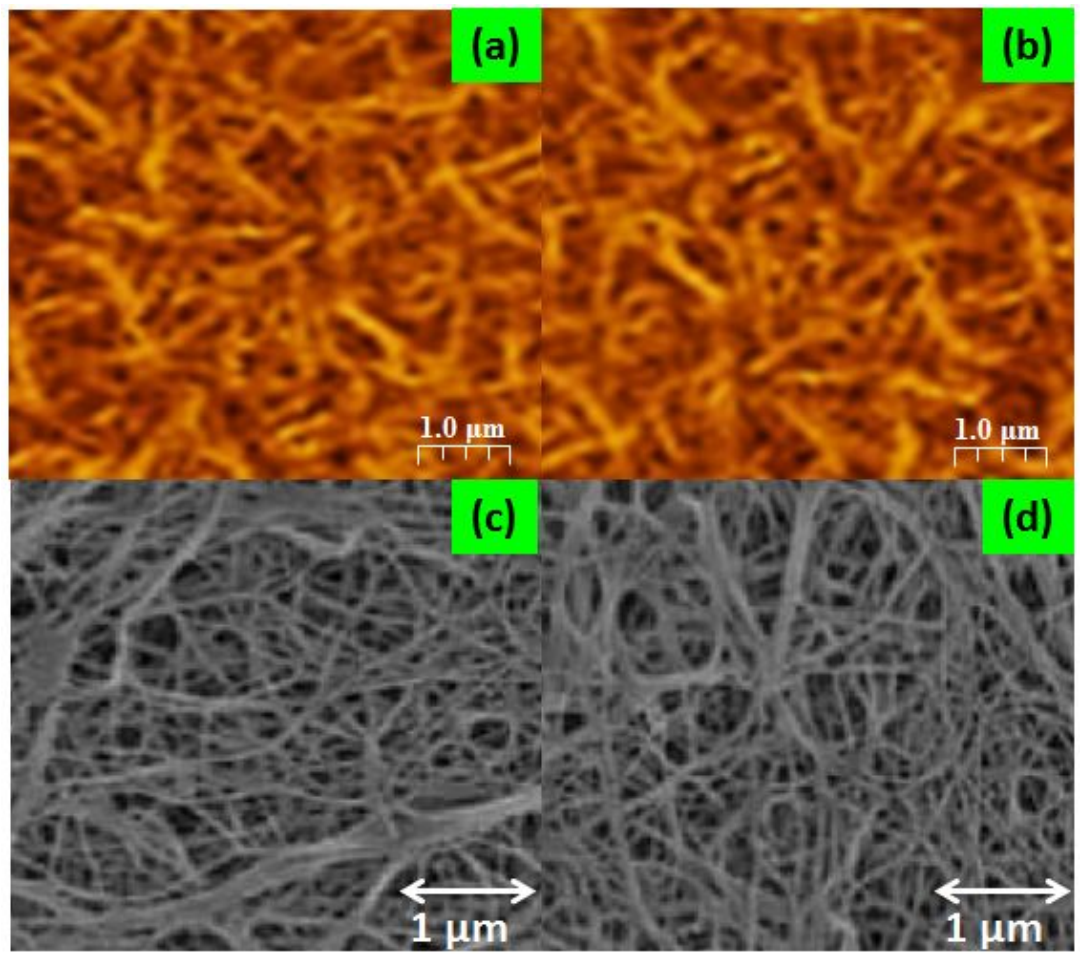

Figure S17. AFM and SEM images obtained for compound 10c (a,c); compound 10d (b,d) at $1 \mathrm{mM}$ in the dodecane solution (scale bar is $1 \mu \mathrm{m}$ ). 

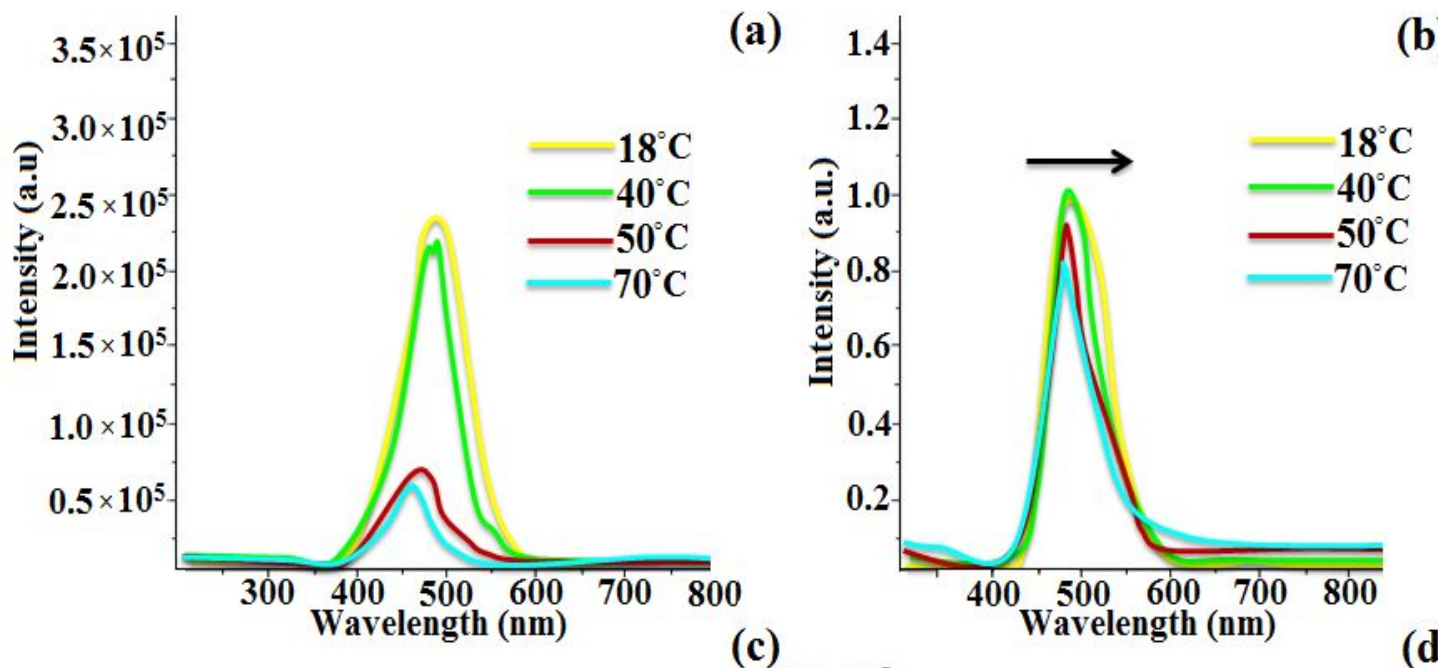

(b)

(c)

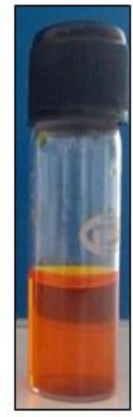

Sol
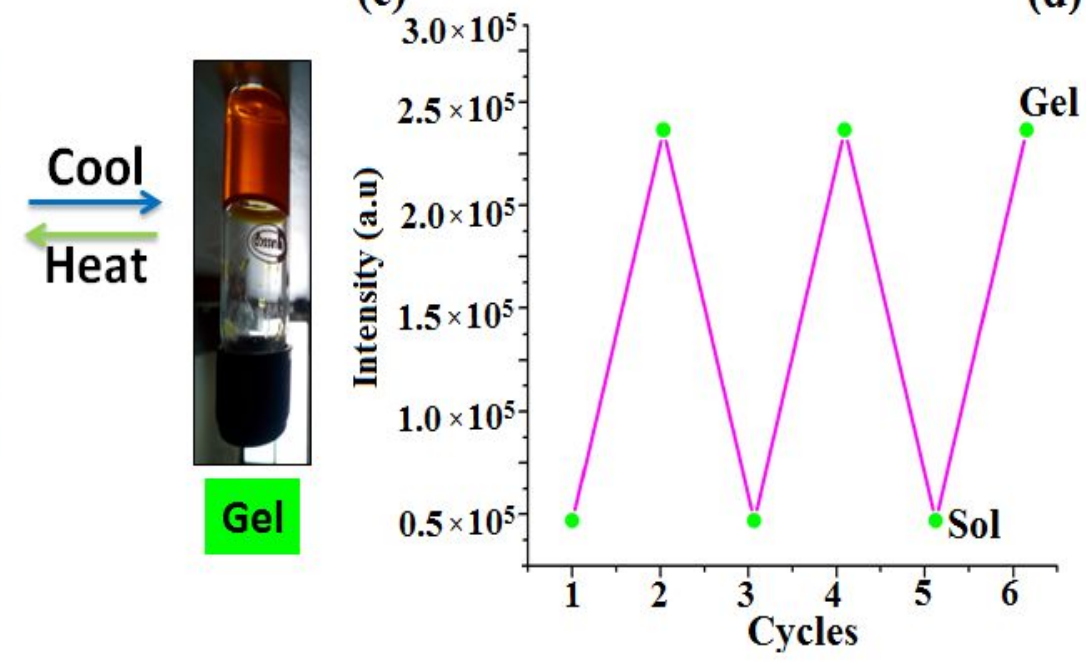

Figure S18. Emission spectra of compound 10c showing an increase in the emission intensity on decreasing temperature due to gelation (a); normalized emission spectra showing a red shift on gelation (b); image of formation of gel from solution (c); reproducible reversibility of emission intensity in solution to gel interconversion (d). 


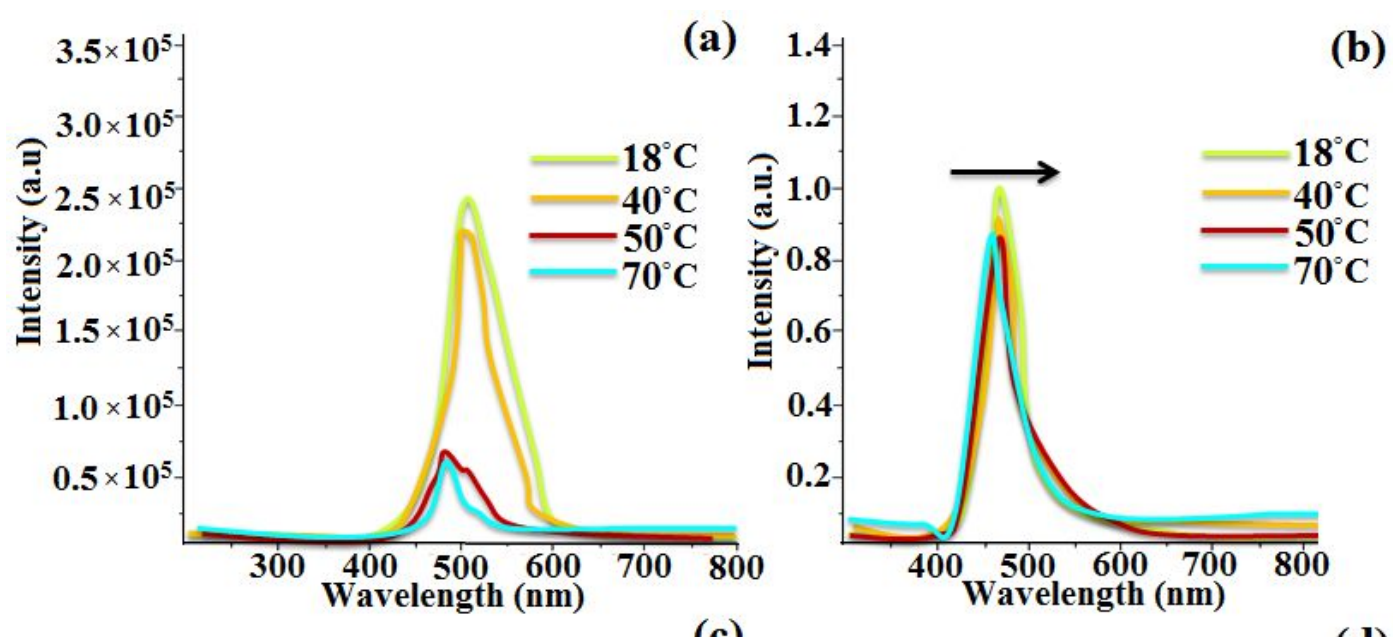

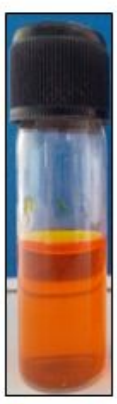

Sol

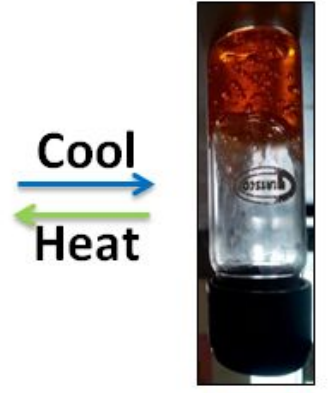

Gel (c)

(d)

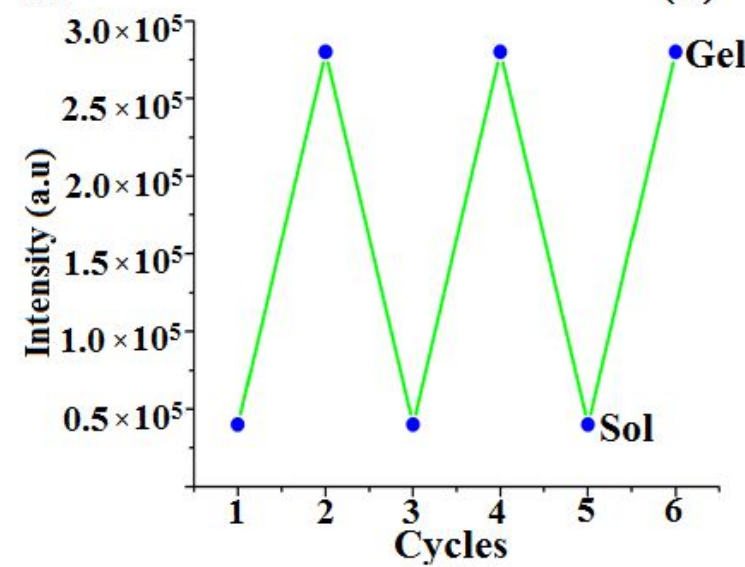

Figure S19. Emission spectra of compound 10d showing an increase in the emission intensity on decreasing temperature due to gelation (a); normalized emission spectra showing a red shift on gelation (b); image of formation of gel from solution (c); reproducible reversibility of emission intensity in solution to gel interconversion (d).
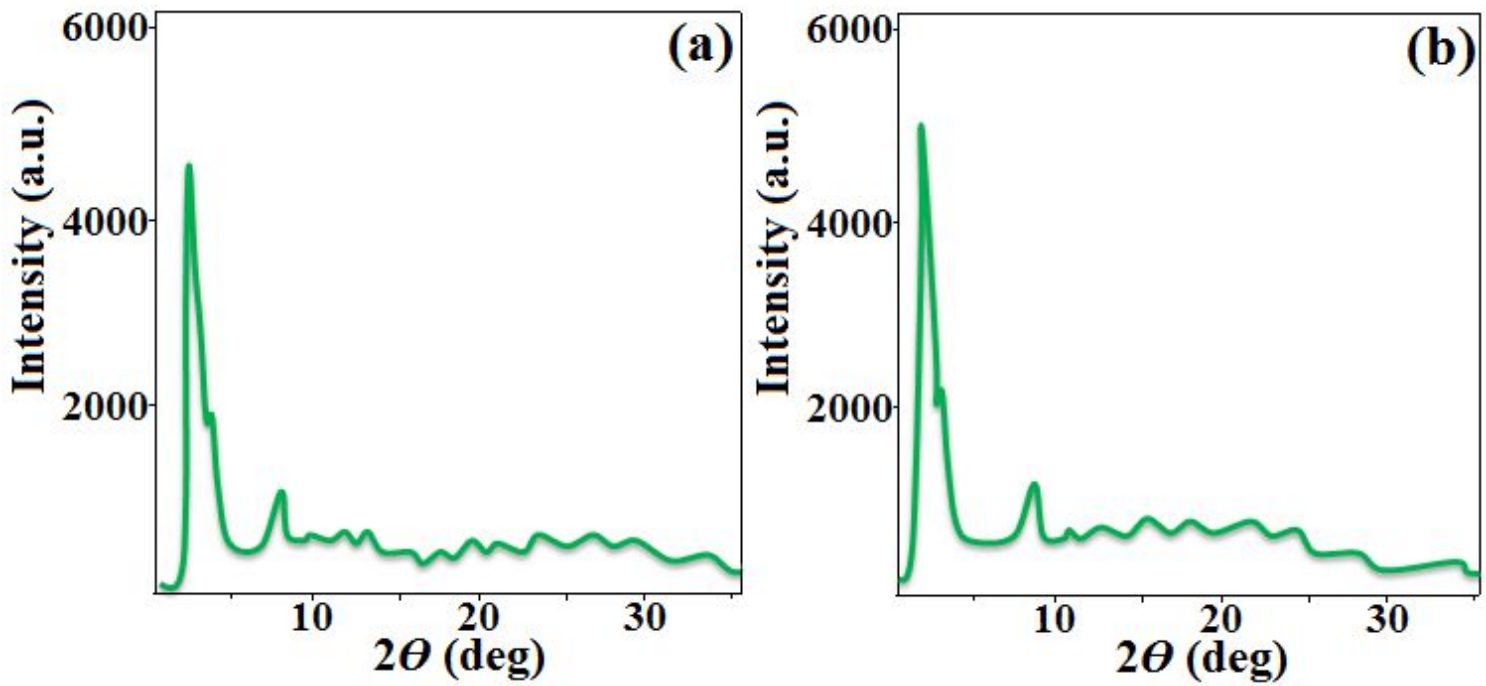

Figure S20. XRD profile depicting the intensity against the $2 \theta$ obtained for the $\mathrm{Col}_{\mathrm{r}}$ phase of compounds 10c (a); compound 10d (b) in xerogels state. 
Table $\mathbf{S}_{3}$. Results of (hkl) indexation of XRD profiles of the compound 10c in xerogel state at room temperature.

\begin{tabular}{|c|c|c|c|c|}
\hline $\begin{array}{l}\text { Compound } \\
\text { (D/Å) }\end{array}$ & $\begin{array}{l}\text { Phase } \\
\left(\mathrm{T} /{ }^{\circ} \mathrm{C}\right)\end{array}$ & $\operatorname{dobs}(\AA)$ & Miller indices & $\begin{array}{c}\text { Lattice } \\
\text { Parameters } \\
\text { (§) }\end{array}$ \\
\hline \multirow{7}{*}{$10 \mathrm{c}$} & \multirow{7}{*}{$\begin{array}{l}\text { Colr } \\
(\mathrm{RT})\end{array}$} & 32.76 & 200 & \\
\hline & & 20.26 & 110 & \\
\hline & & 10.38 & 340 & $\mathrm{a}=65.22$ \\
\hline & & 7.05 & 240 & $\mathrm{~b}=28.97$ \\
\hline & & 4.49 & 440 & \\
\hline & & 3.77 & 520 & \\
\hline & & 3.18 & 630 & \\
\hline
\end{tabular}

Table $\mathbf{S}_{4}$. Results of $(\mathrm{hkl})$ indexation of XRD profiles of the compound $\mathbf{1 0 d}$ in xerogel state at room temperature.

\begin{tabular}{|c|c|c|c|c|}
\hline $\begin{array}{l}\text { Compound } \\
\text { (D/Å) }\end{array}$ & $\begin{array}{l}\text { Phase } \\
\left(\mathrm{T} /{ }^{\circ} \mathrm{C}\right)\end{array}$ & $\operatorname{dobs}(\AA ̊)$ & Miller indices & $\begin{array}{c}\text { Lattice } \\
\text { Parameters } \\
\text { (§) }\end{array}$ \\
\hline & & 34.06 & 200 & \\
\hline & & 20.18 & 110 & \\
\hline & & 10.38 & 320 & $a=63.72$ \\
\hline
\end{tabular}




\begin{tabular}{|l|l|c|c|c|}
\hline 10d & \multirow{2}{*}{$\begin{array}{c}\text { Colr } \\
\text { (RT) }\end{array}$} & 7.05 & 240 & $\mathrm{~b}=28.85$ \\
\cline { 3 - 5 } & & 4.69 & 430 & \\
\cline { 3 - 5 } & & 3.77 & 540 & \\
\cline { 3 - 5 } & & 3.18 & 640 & \\
\cline { 3 - 5 } & & & & \\
\hline
\end{tabular}

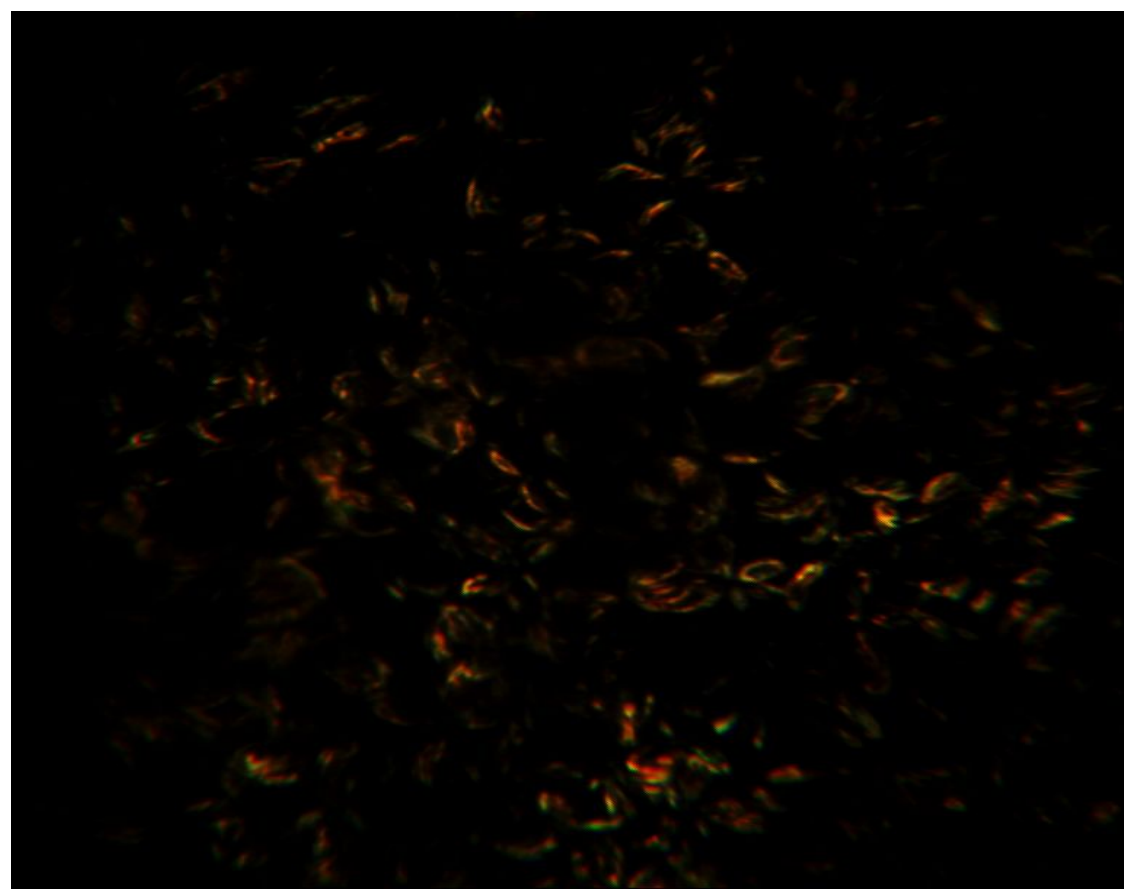

Figure S21. POM image of the xerogel showing a birefringent texture of comp.10C. 
Table $\mathbf{S}_{\mathbf{5}}$. Electroluminescent performance data of OLEDs ${ }^{\mathrm{a}}$

\begin{tabular}{|c|c|c|c|c|c|c|c|}
\hline $\begin{array}{c}\text { Doping } \\
\text { concentration }\end{array}$ & $\begin{array}{c}\text { Vonse }^{\mathrm{b}} \\
\text { (V) }\end{array}$ & $\begin{array}{c}\eta_{p}{ }^{c} \\
\left(\operatorname{lm} W^{-1}\right)\end{array}$ & $\begin{array}{c}\eta_{c}^{d} \\
\left(\operatorname{cdA}^{-1}\right)\end{array}$ & $\begin{array}{l}\mathrm{EQE}^{\mathrm{e}} \\
(\%)\end{array}$ & $\operatorname{CIE}(x, y)^{f}$ & $\begin{array}{l}\operatorname{Lmax}^{g} \\
\left(\mathrm{~cd} / \mathrm{m}^{2}\right)\end{array}$ & $\begin{array}{c}\lambda \mathrm{em}^{\mathrm{h}} \\
(\mathrm{nm})\end{array}$ \\
\hline 1 & 6.2 & 0.2 & 0.6 & 0.8 & $(0.24,0.33)$ & 438 & 496 \\
\hline 2 & 6.7 & 0.1 & 0.6 & 0.6 & $(0.24,0.33)$ & 407 & 494 \\
\hline 5 & 7.2 & 0.2 & 0.3 & 0.6 & $(0.24,0.33)$ & 353 & 496 \\
\hline 6 & 6.9 & 0.2 & 0.5 & 0.3 & $(0.24,0.32)$ & 314 & 482 \\
\hline Neat & 7.4 & 0.2 & 0.6 & 0.4 & $(0.24,0.31)$ & 286 & 484 \\
\hline
\end{tabular}

${ }^{a}$ :Device configuration ITO/PEDOT/emissive layer or doped with CBP/TPBi/LIF/Al, bVonset: turn-on voltage at luminance of $100 \mathrm{~cd} / \mathrm{m}^{2}$. Power efficiency $\left(n_{\mathrm{p}}\right)$, current efficiency $\left(\eta_{c}\right)$. EQEe external quantum efficiency, CIE $(\mathrm{x}, \mathrm{y})^{\mathrm{f}}$ : Colour coordinates, Lmax $\mathrm{g}$ : maximum luminance of the device, $\lambda \mathrm{em}^{\mathrm{h}}$ : emission maximum wavelength.
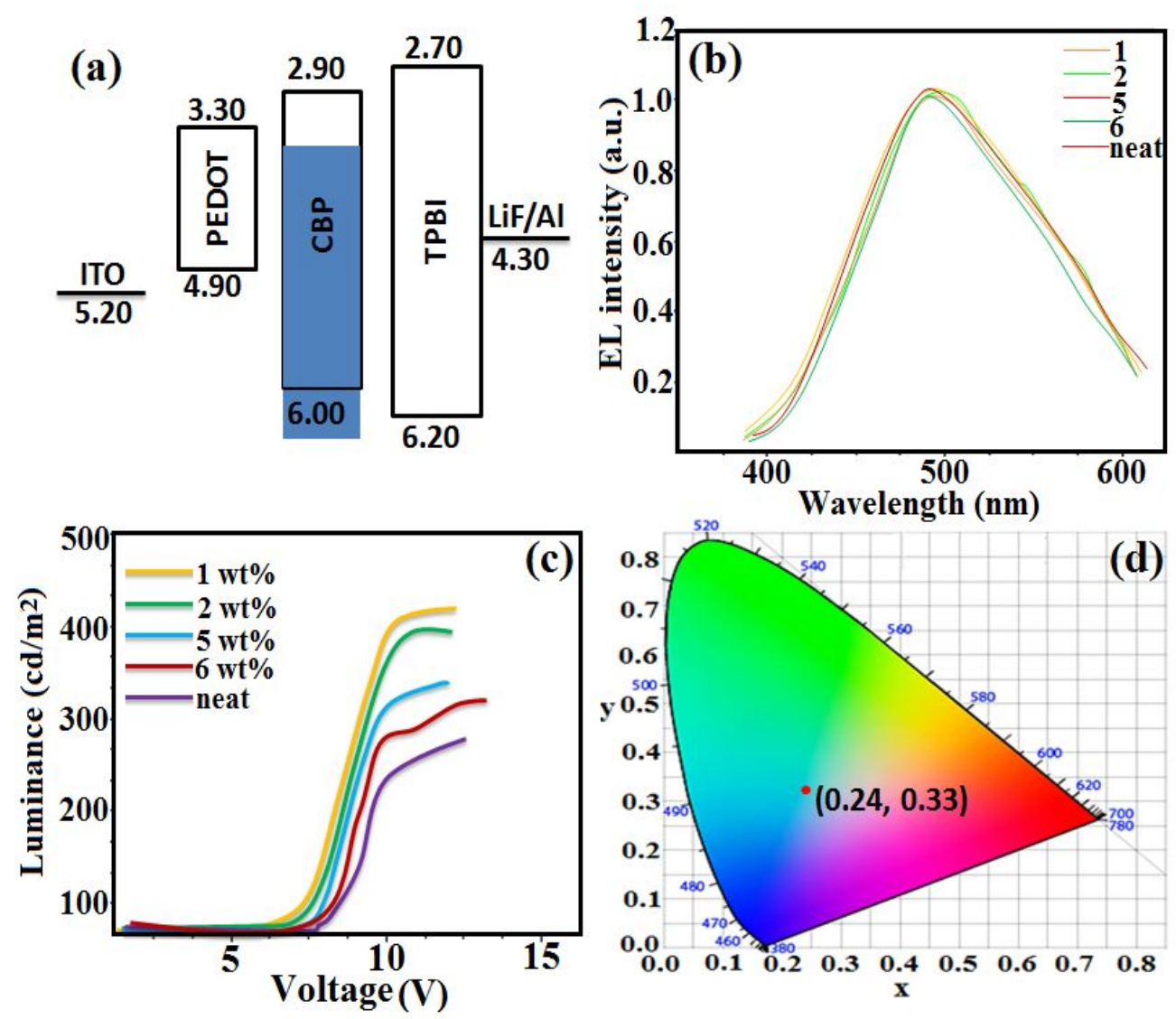
Figure S22. (a) Energy-level diagram of the compound 10c used for the fabrication of (CBP) host OLED device configuration as ITO/PEDOT/emissive layer/TPBi/LiF/Al, (b) EL spectra of OLED devices with various doping concentrations and neat film of compound 10c, (c) luminance vs voltage plots of the solution proceed OLED device at different doping concentrations and (d) CIE chromatogram of dye doped compound 10c (1 wt.\%) of the device.
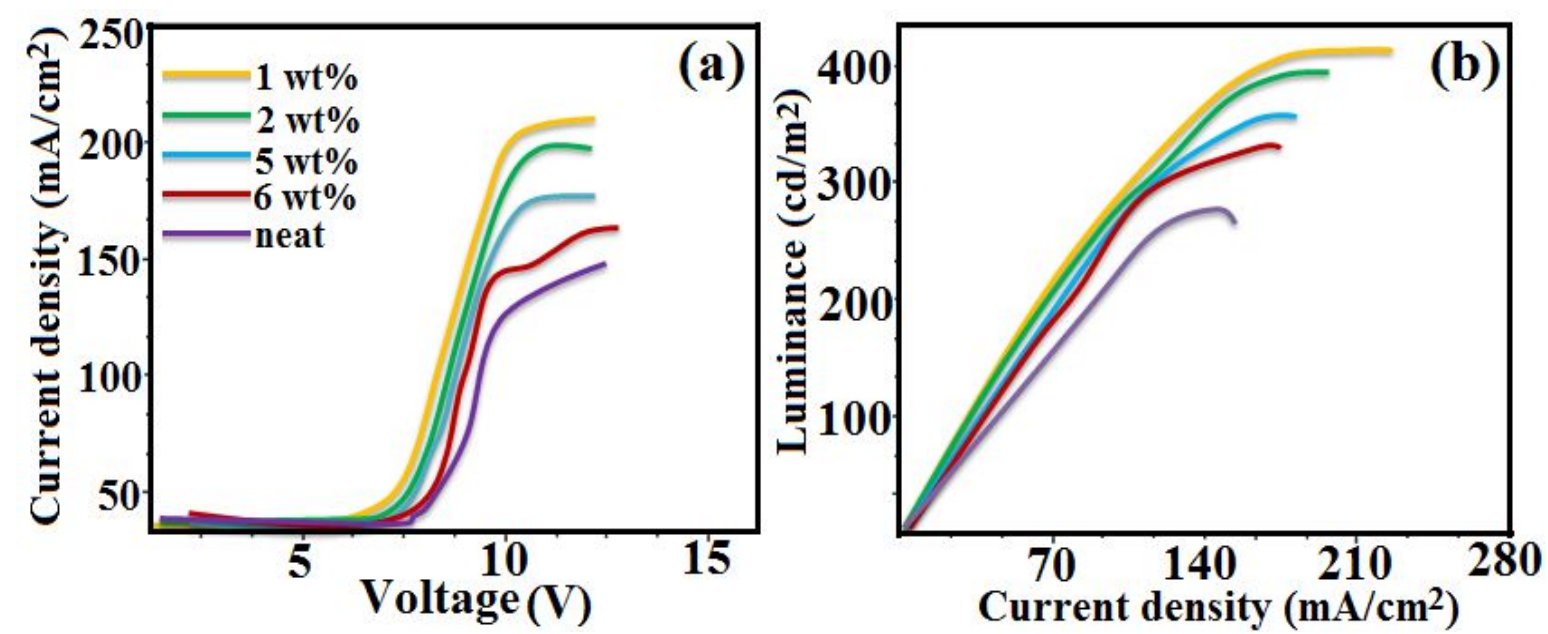

Figure S23. (a) Current density vs voltage, (b) luminance vs current density of OLED devices at different doping concentrations of compound 10c. 


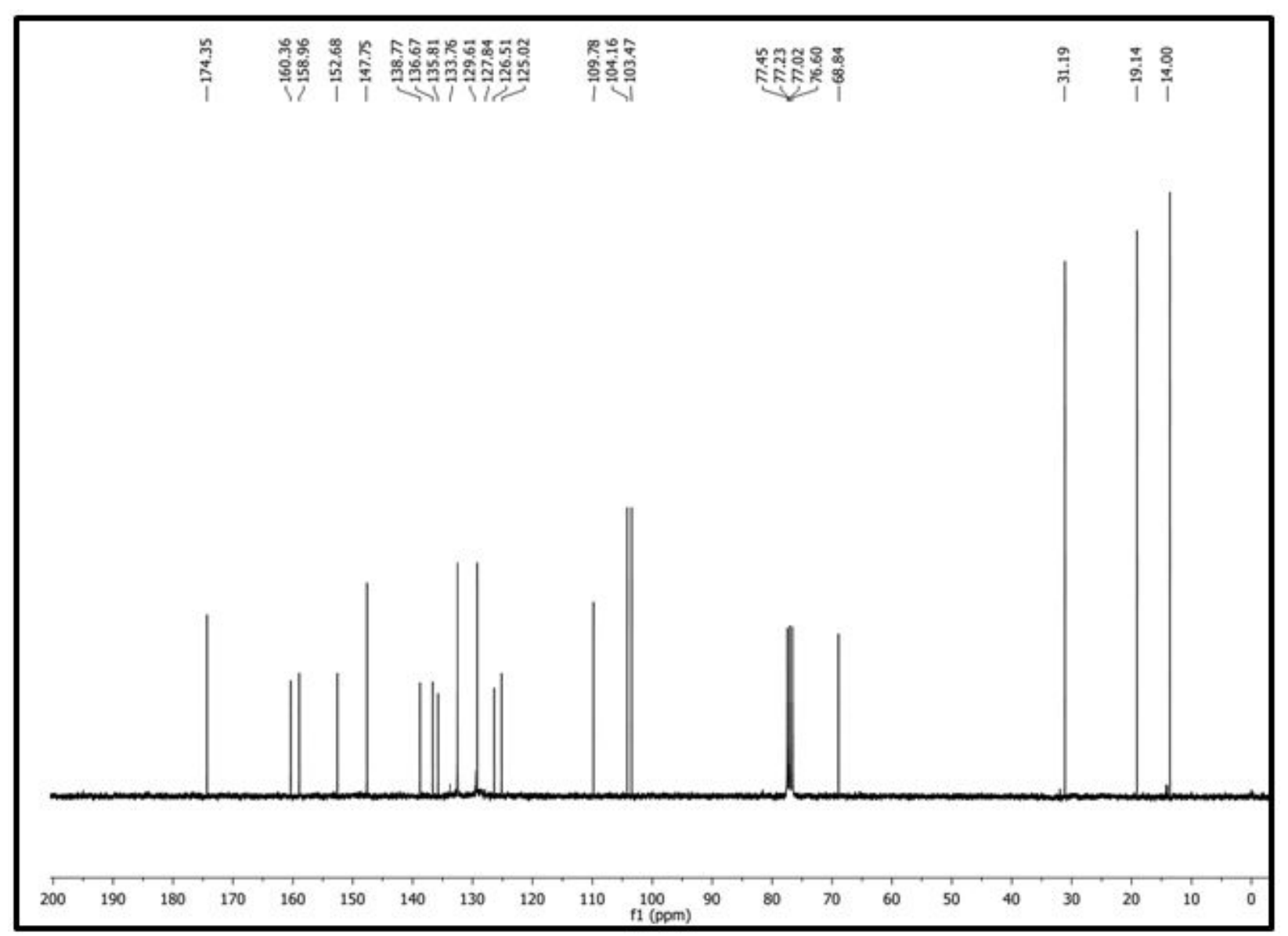

Figure S24. ${ }^{13} \mathrm{C}$ NMR of compound 8a 


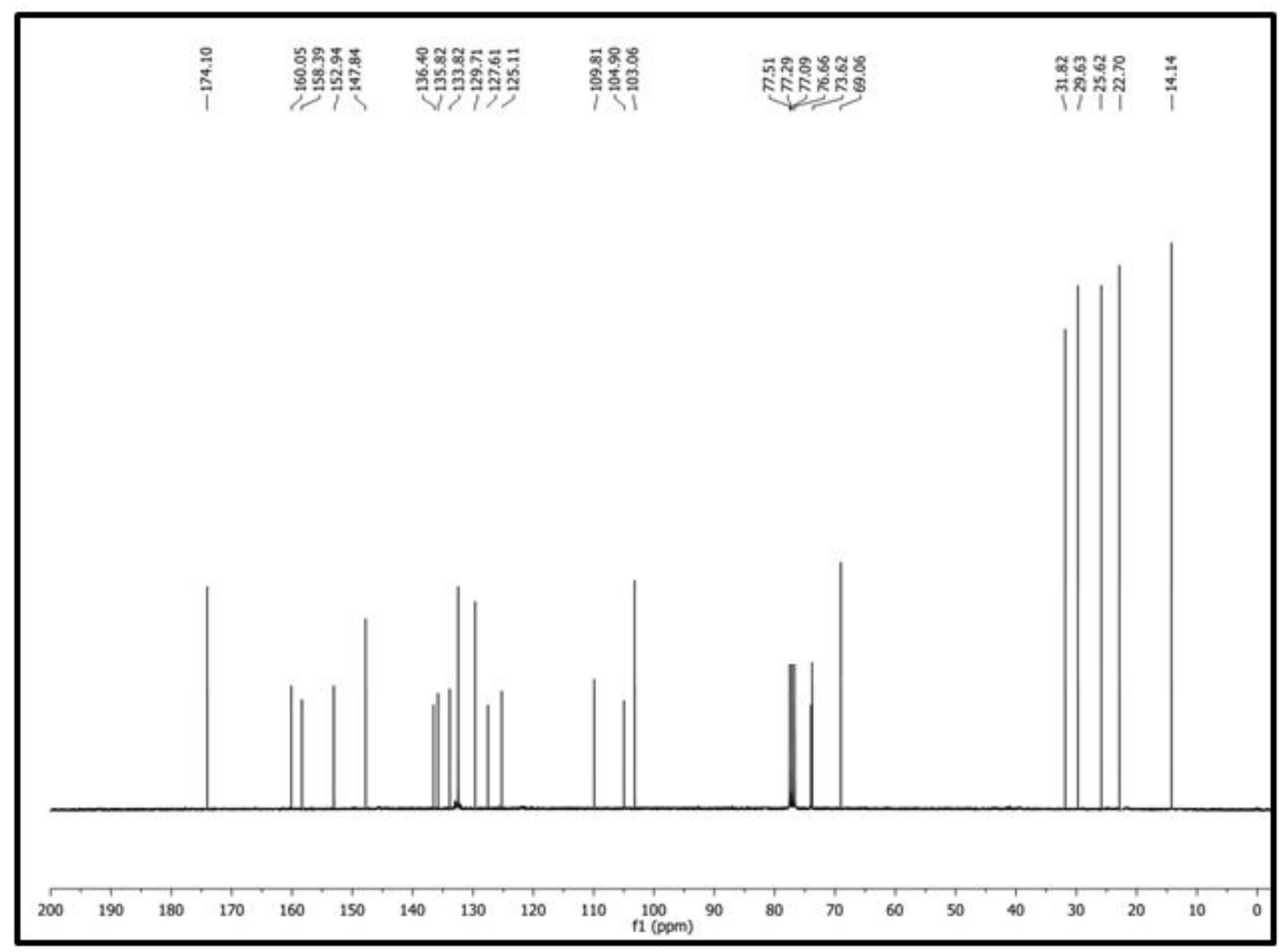

Figure S25. ${ }^{13} \mathrm{C}$ NMR of compound $\mathbf{8 b}$ 


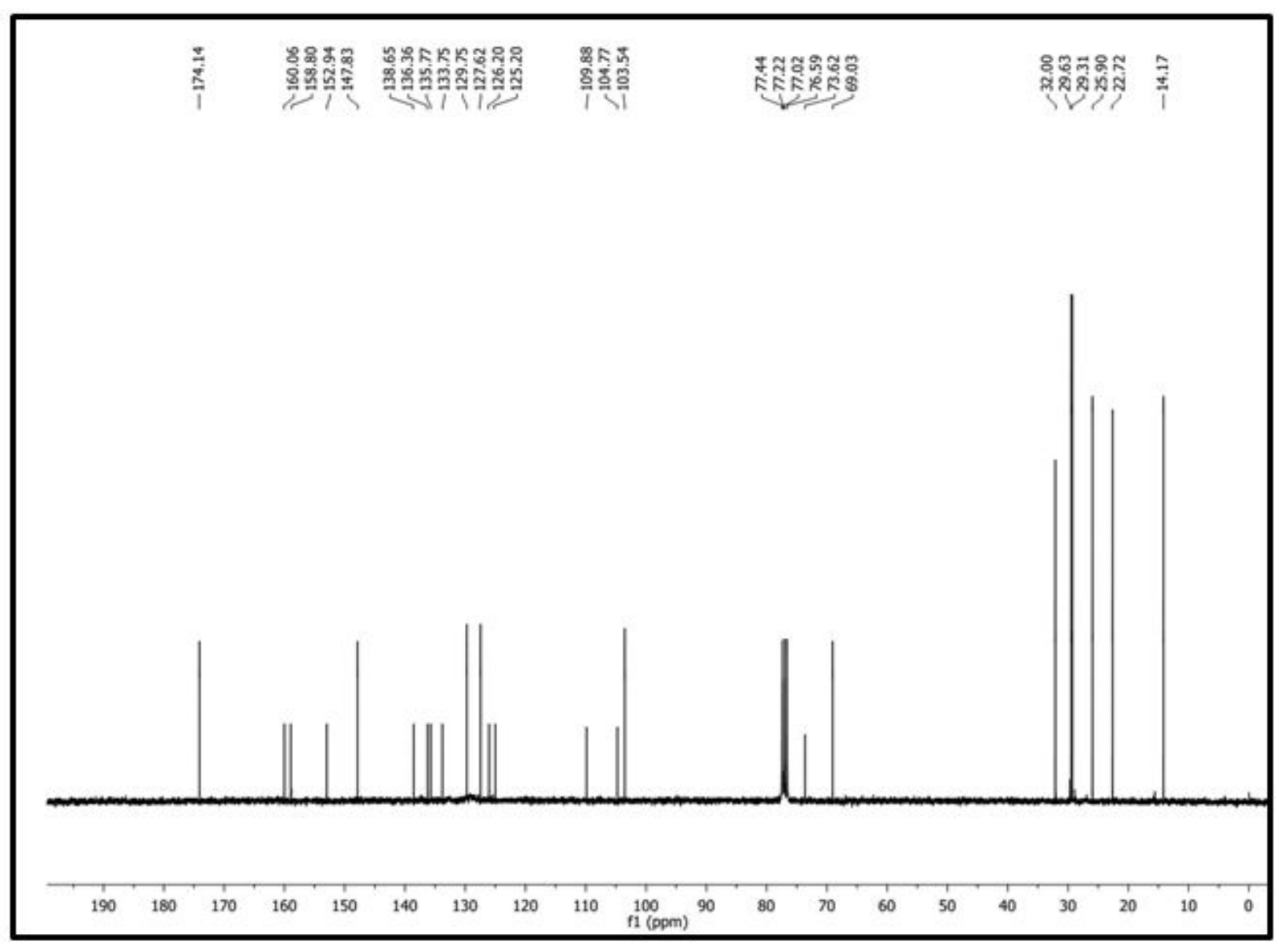

Figure S26. ${ }^{13} \mathrm{C}$ NMR of compound 8c 


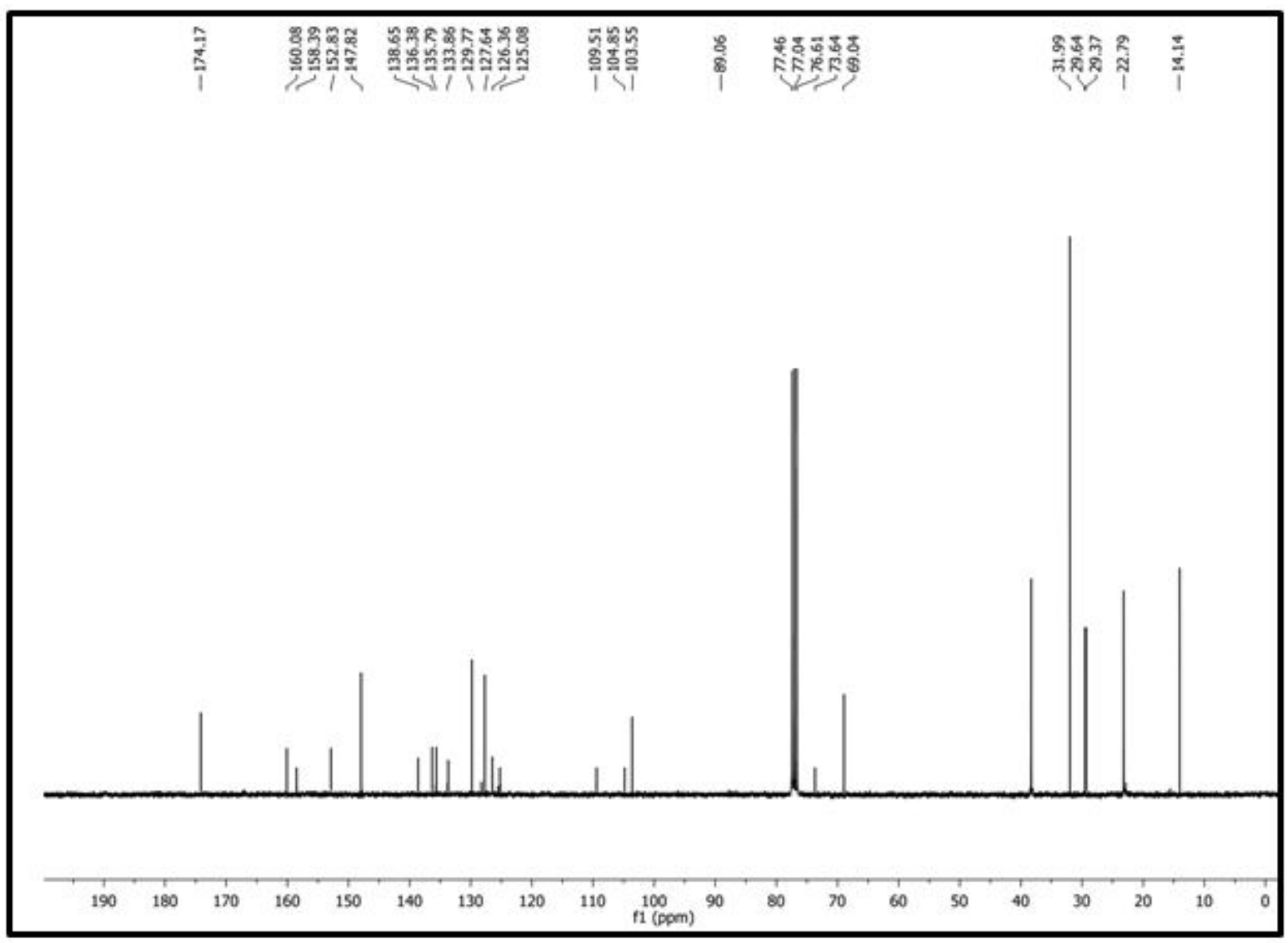

Figure S27. ${ }^{13} \mathrm{C}$ NMR of compound $\mathbf{8 d}$ 


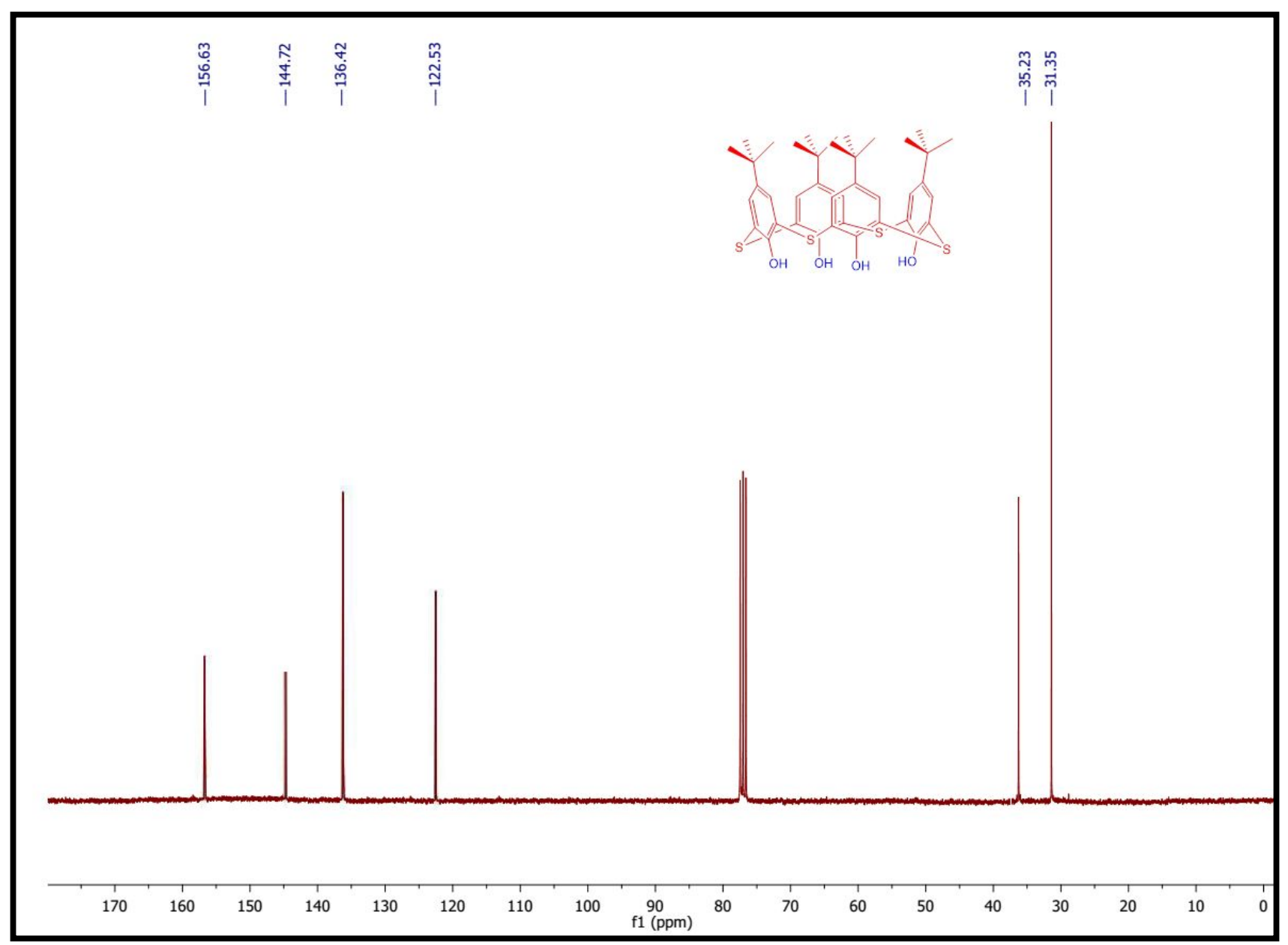

Figure S28. ${ }^{13} \mathrm{C}$ NMR of compound 9 


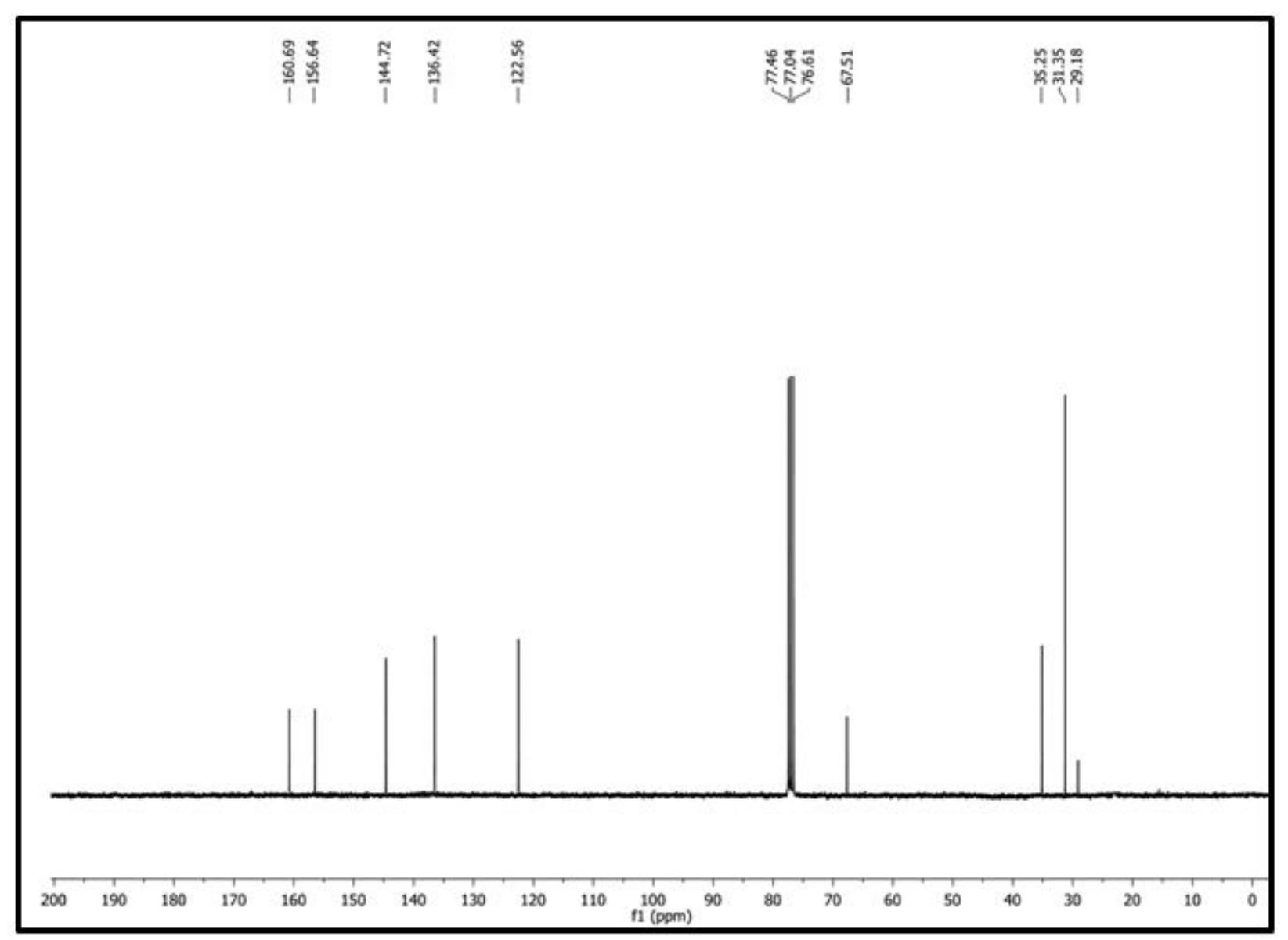

Figure S29. ${ }^{13} \mathrm{C}$ NMR of compound 9a 


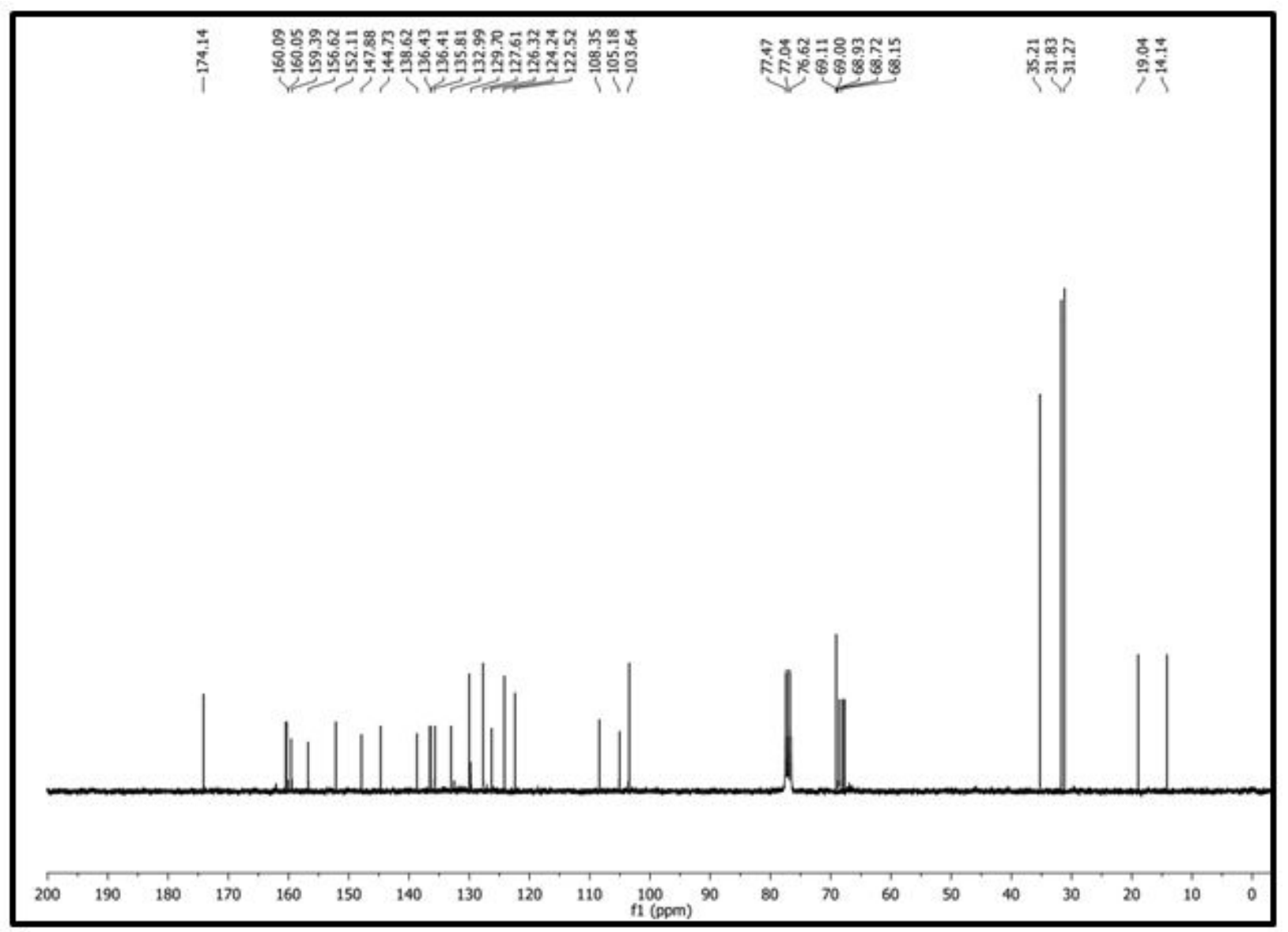

Figure S30. ${ }^{13} \mathrm{C}$ NMR of compound 10a 


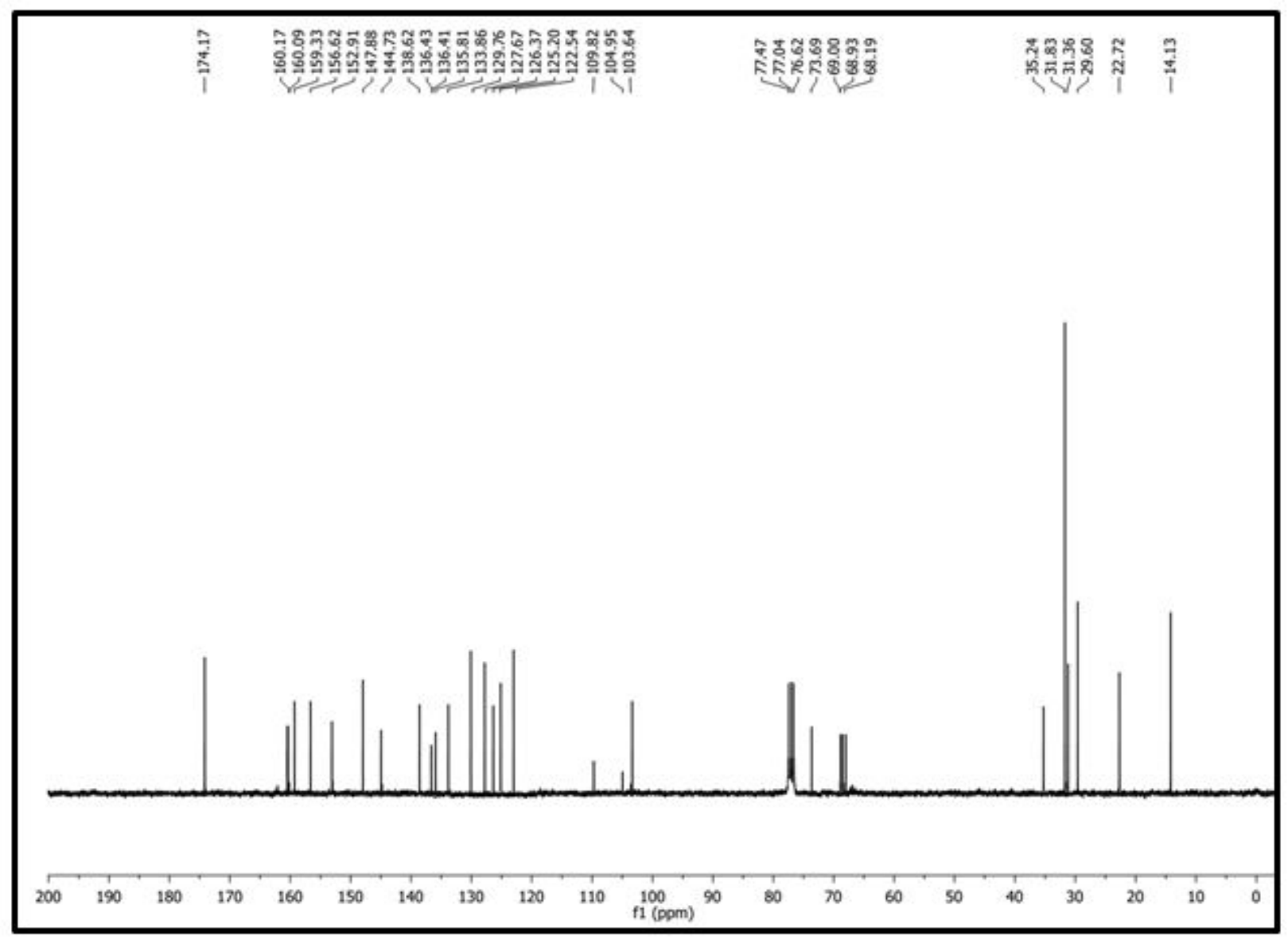

Figure S31. ${ }^{13} \mathrm{C}$ NMR of compound $\mathbf{1 0 b}$ 


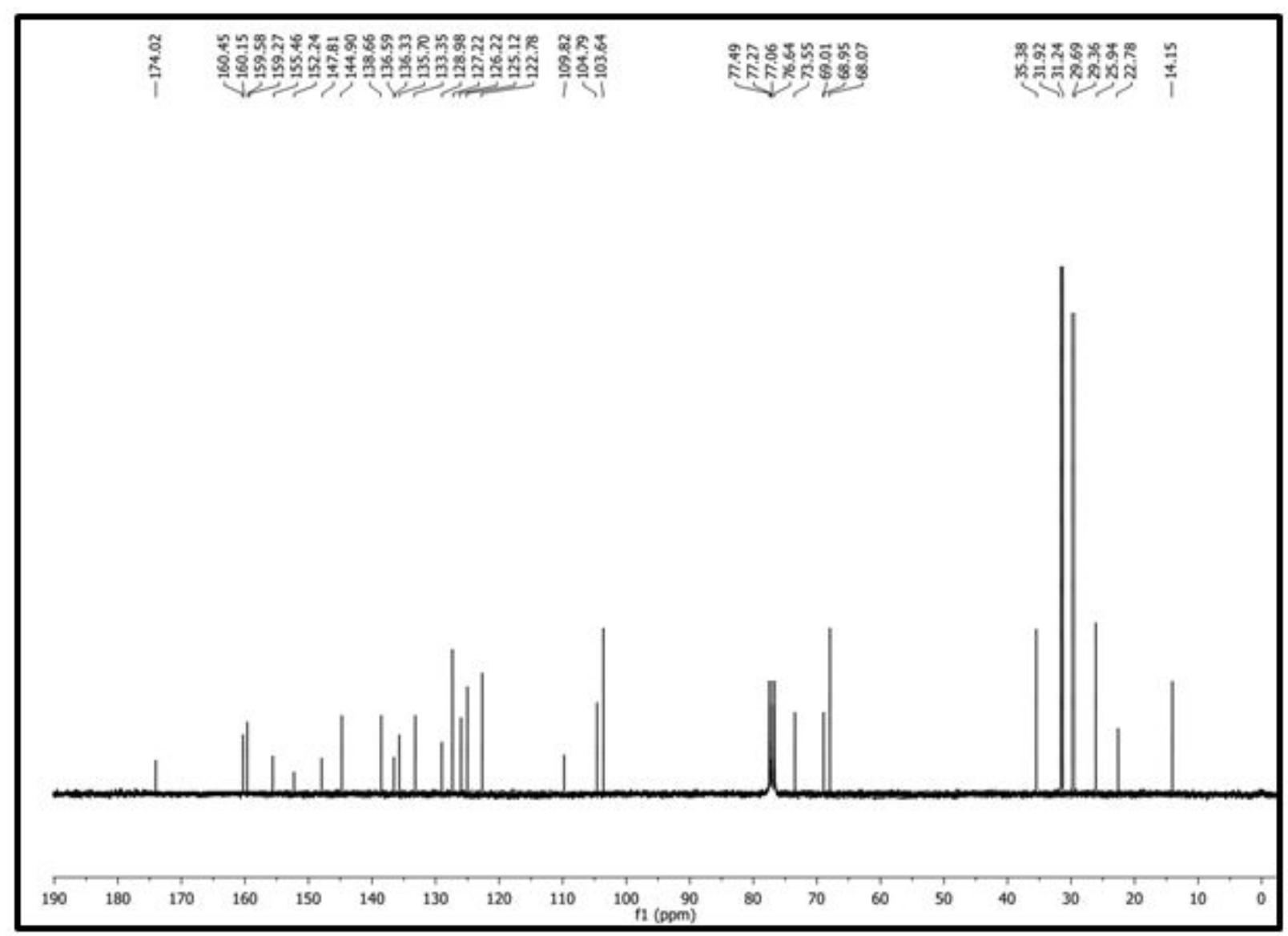

Figure S32. ${ }^{13} \mathrm{C}$ NMR of compound 10c 


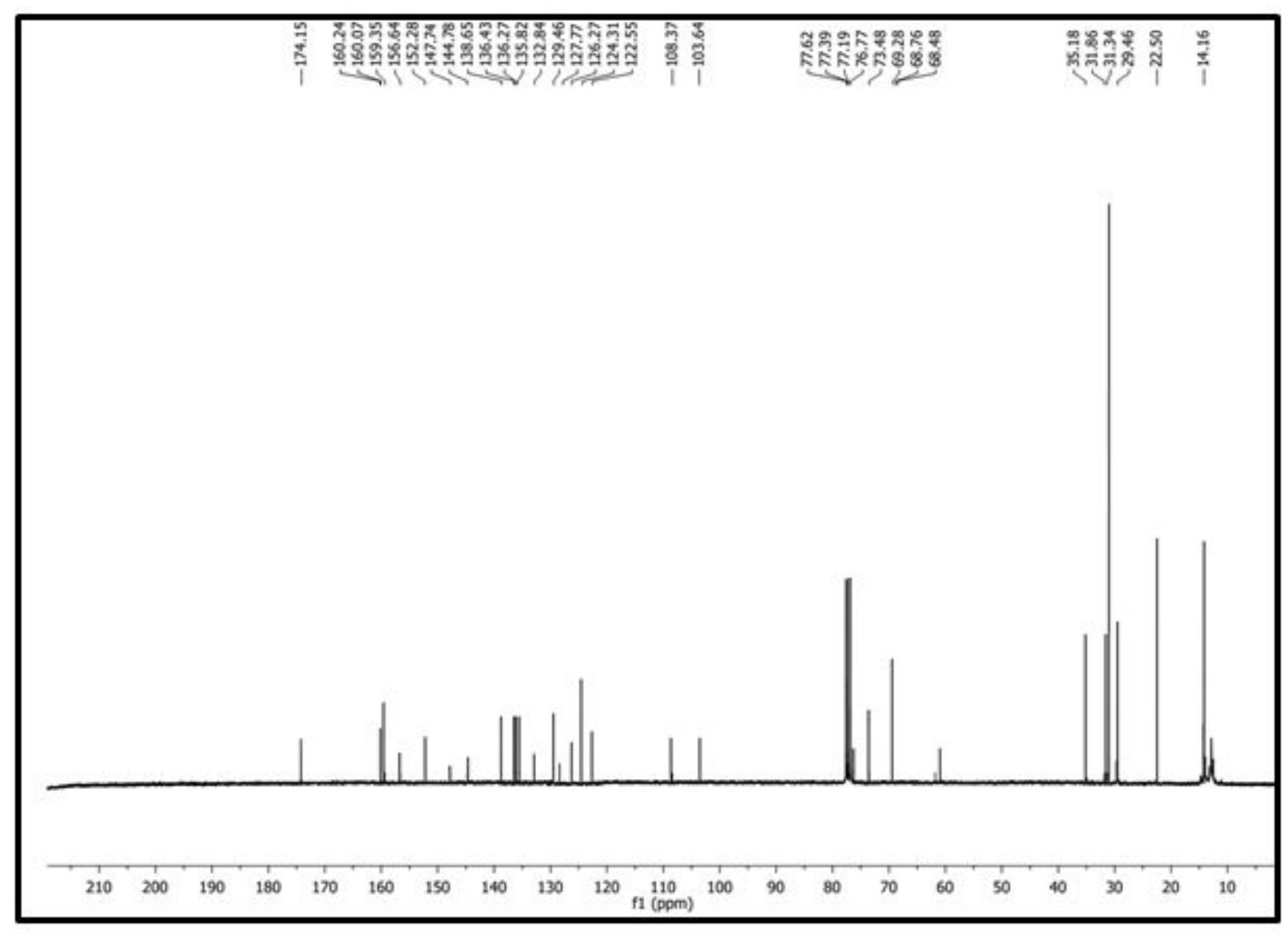

Figure S33. ${ }^{13} \mathrm{C}$ NMR of compound 10d 


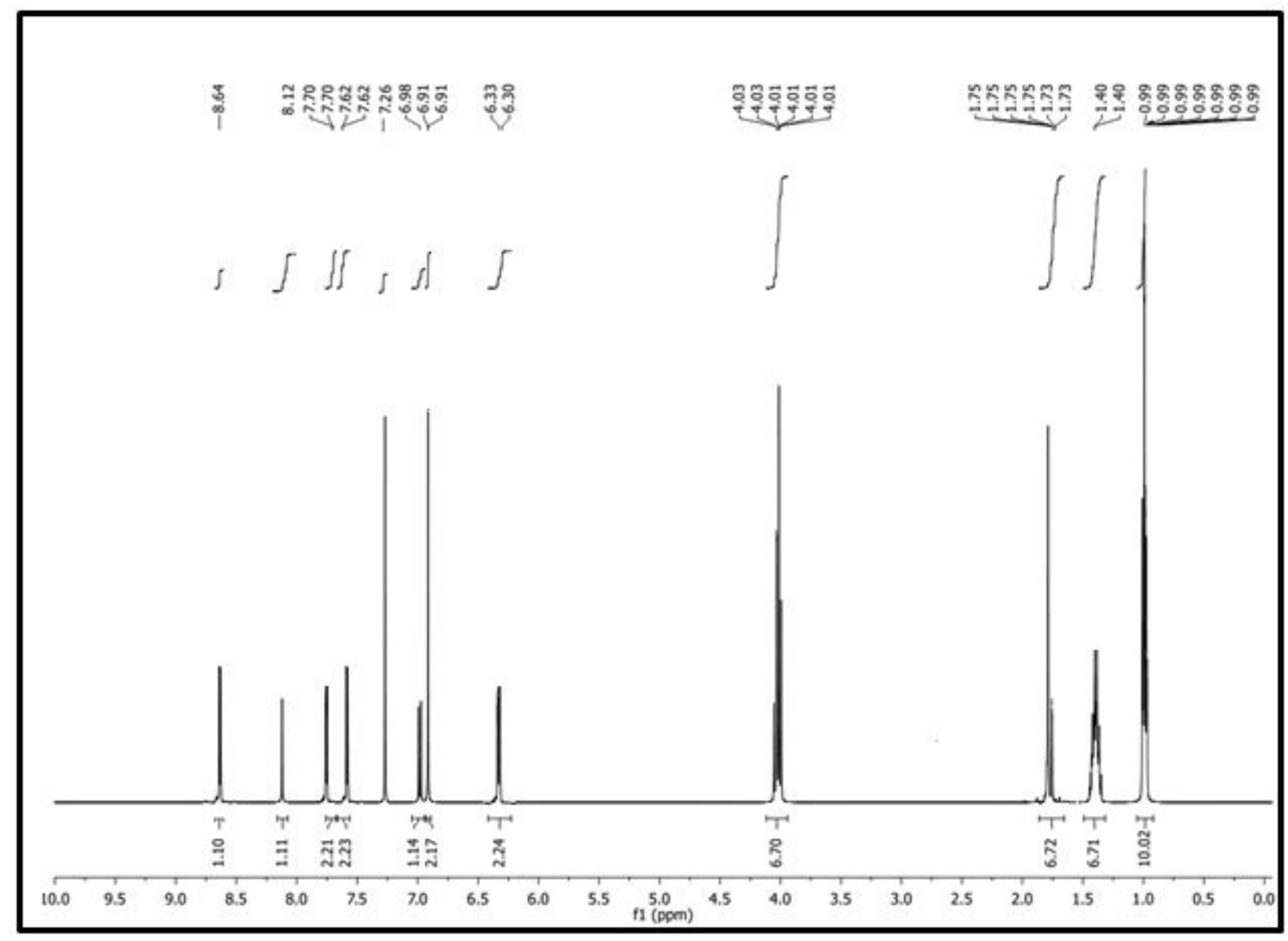

Figure S34. ${ }^{1} \mathrm{H}$ NMR of compound $\mathbf{8 a}$ 


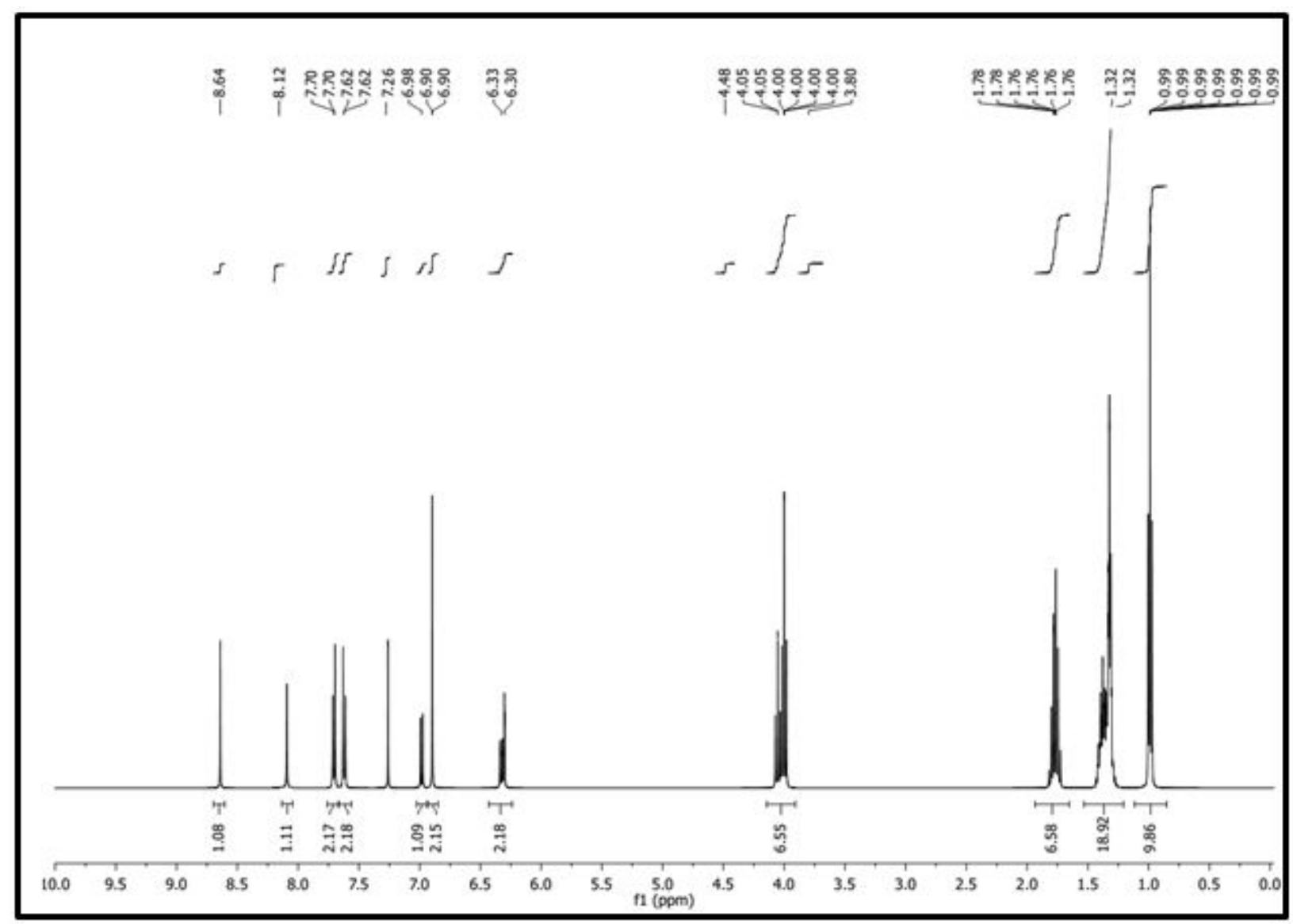

Figure S35. ${ }^{1} \mathrm{H}$ NMR of compound $\mathbf{8 b}$ 


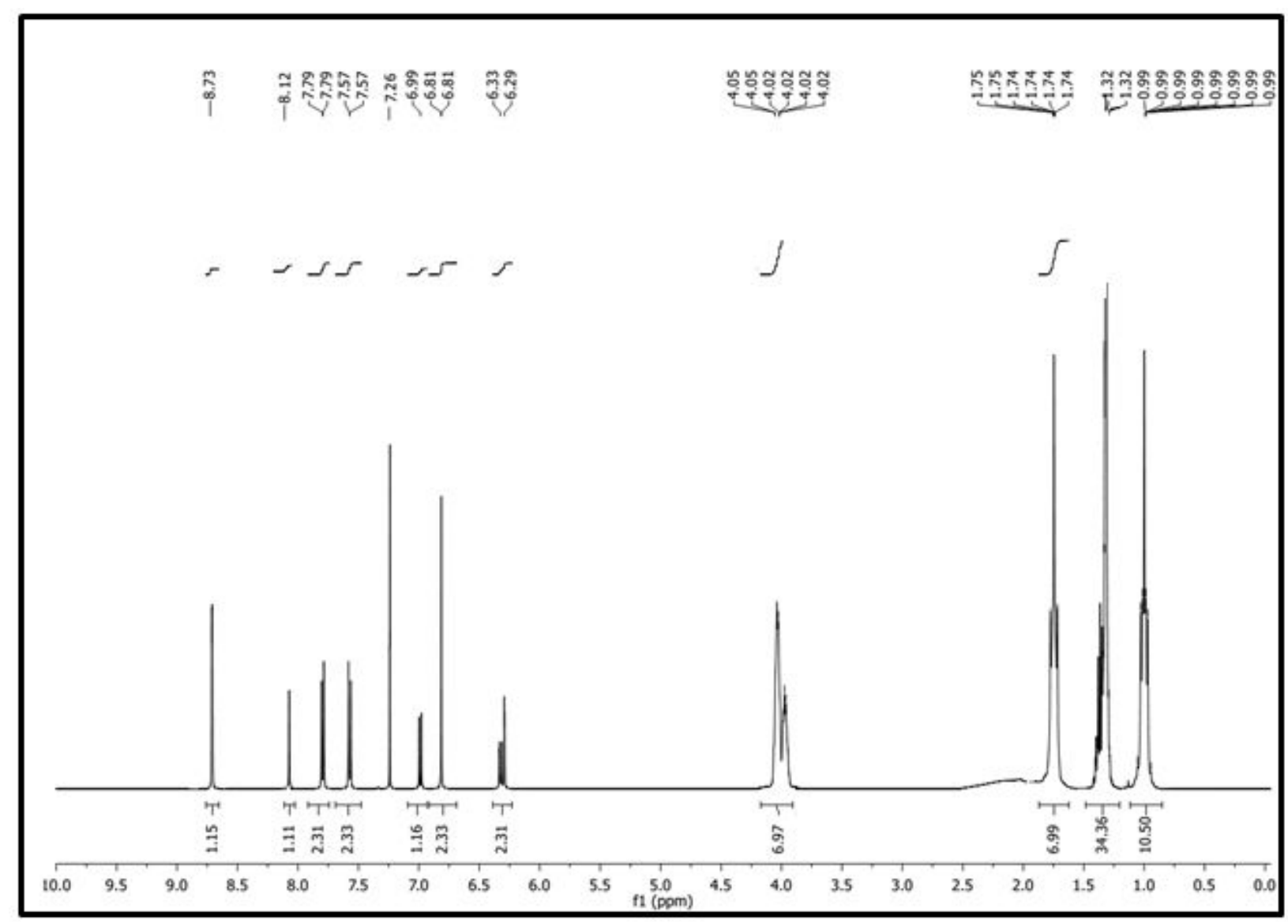

Figure S36. ${ }^{1} \mathrm{H}$ NMR of compound 8c 


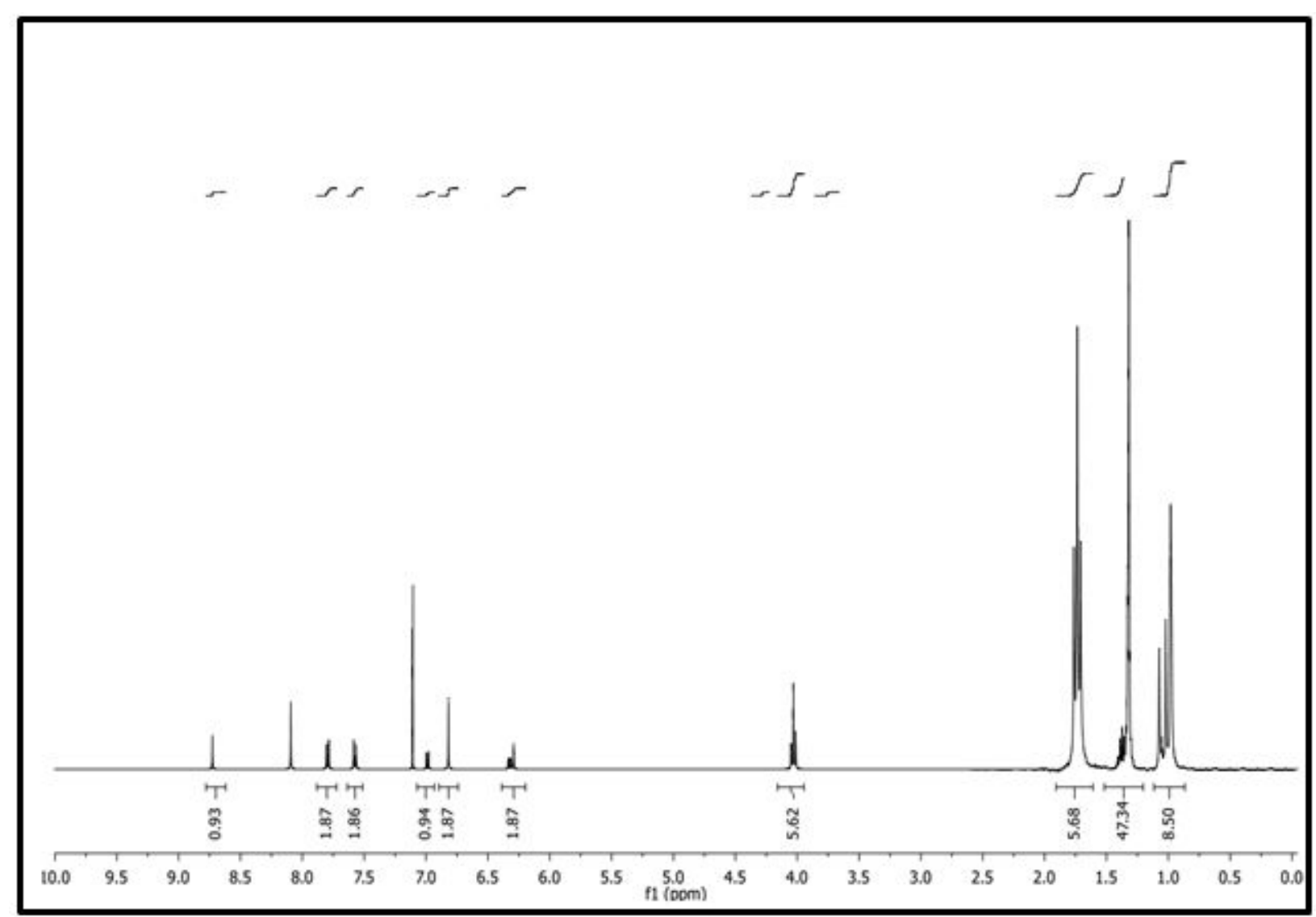

Figure S37. ${ }^{1} \mathrm{H}$ NMR of compound 8d 


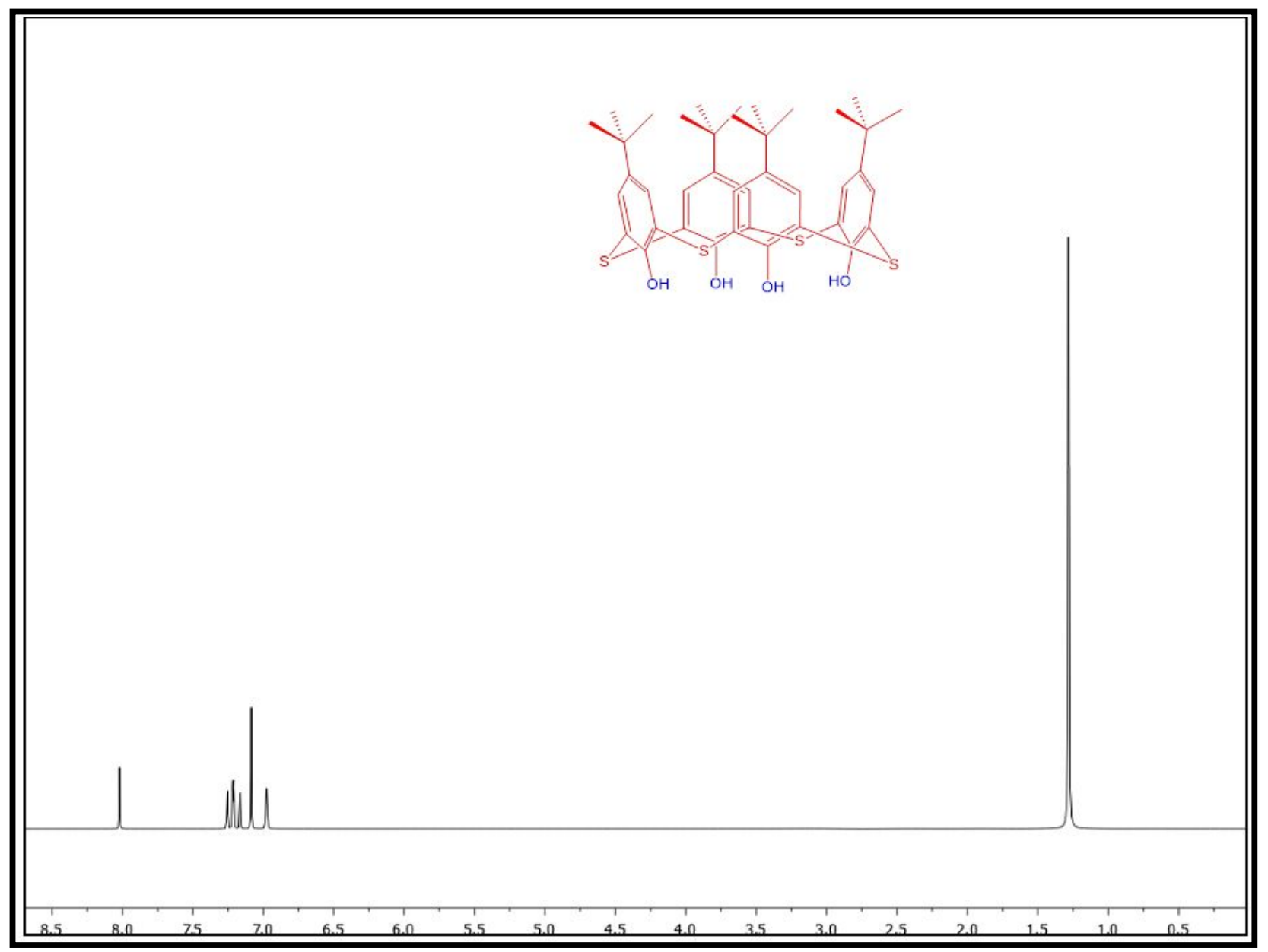

Figure S38. ${ }^{1} \mathrm{H}$ NMR of compound 9 


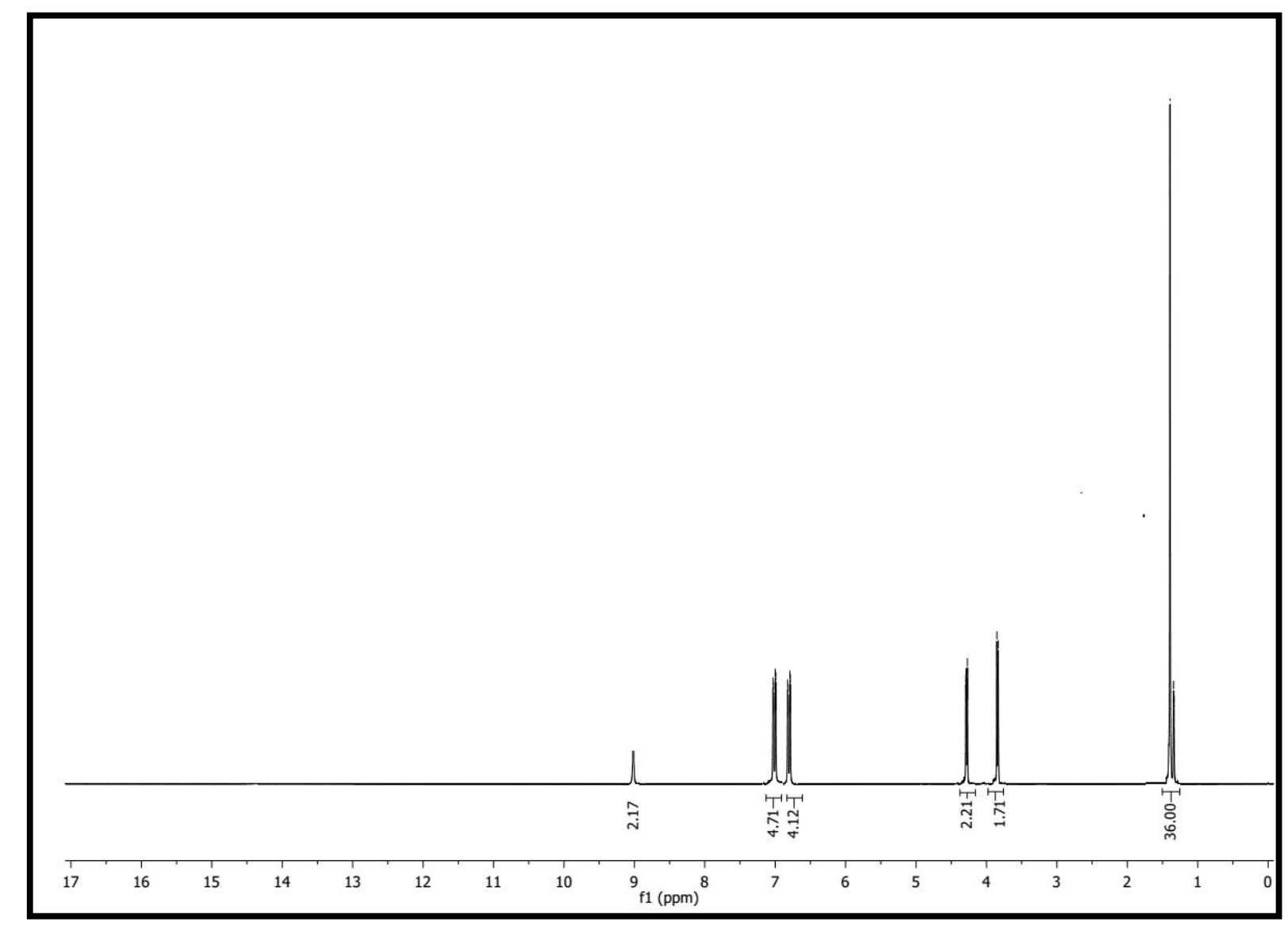

Figure S39. ${ }^{1} \mathrm{H}$ NMR of compound 9a 


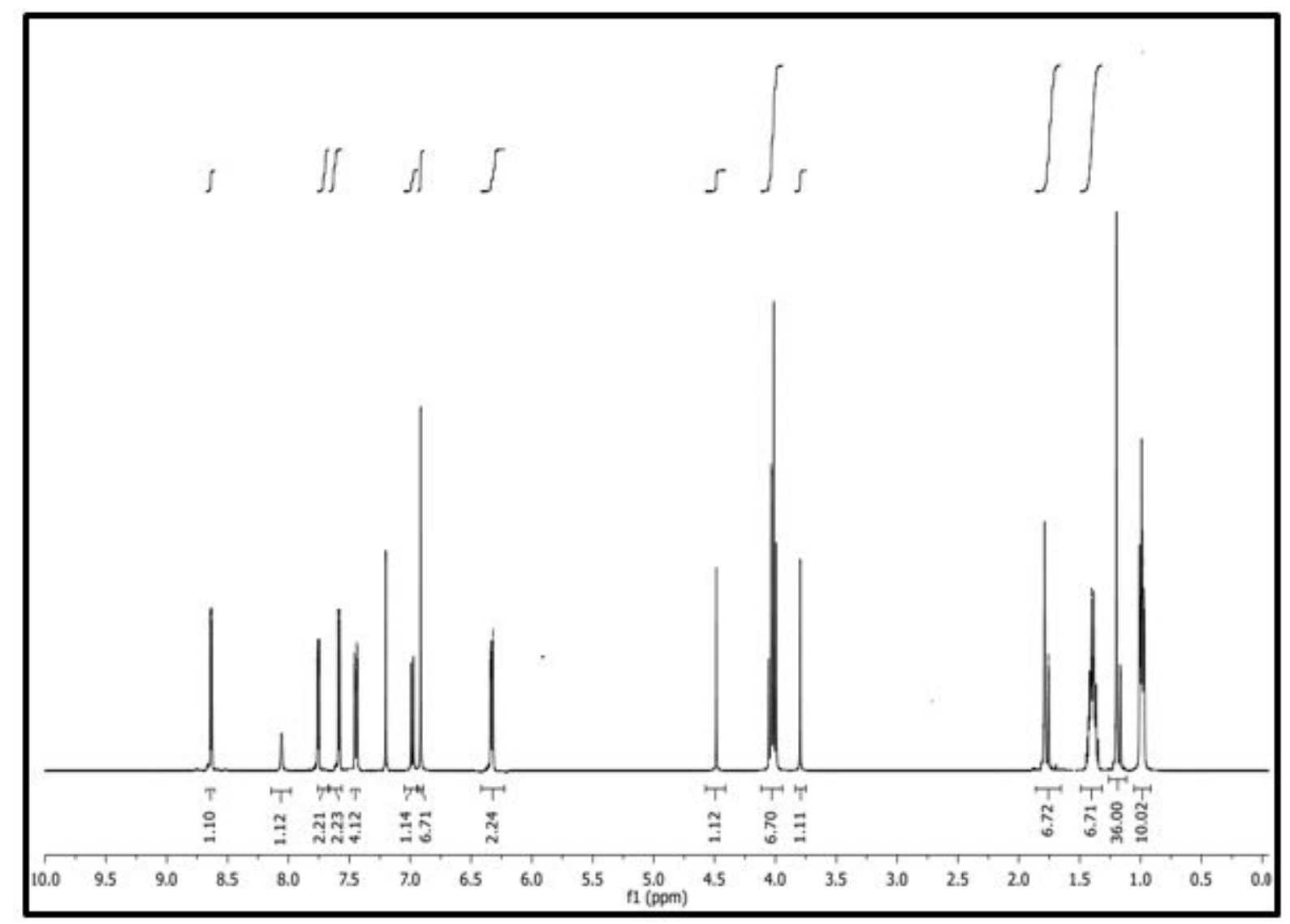

Figure S40. ${ }^{1} \mathrm{H}$ NMR of compound 10a 


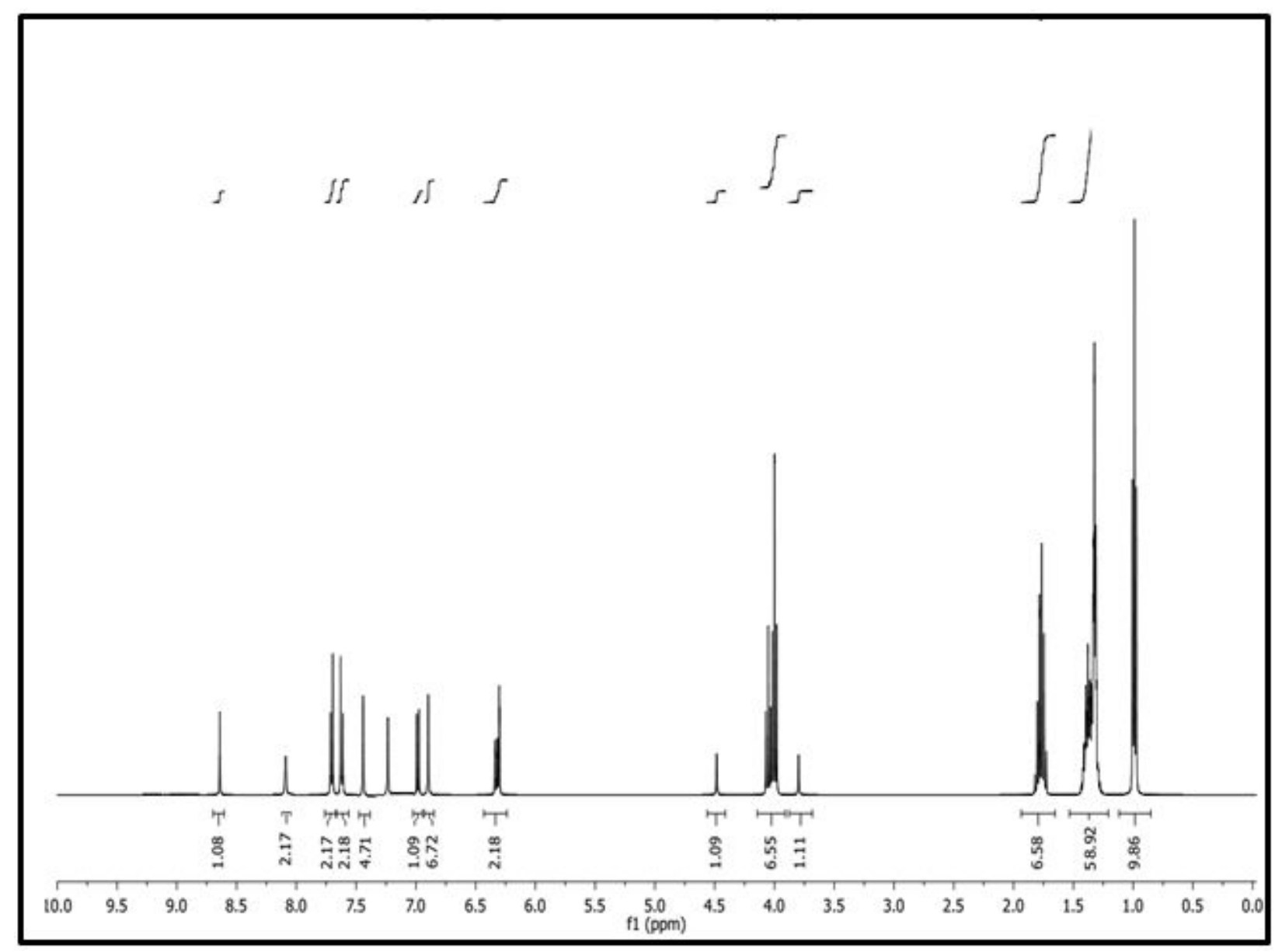

Figure S41. ${ }^{1} \mathrm{H}$ NMR of compound $\mathbf{1 0 b}$ 


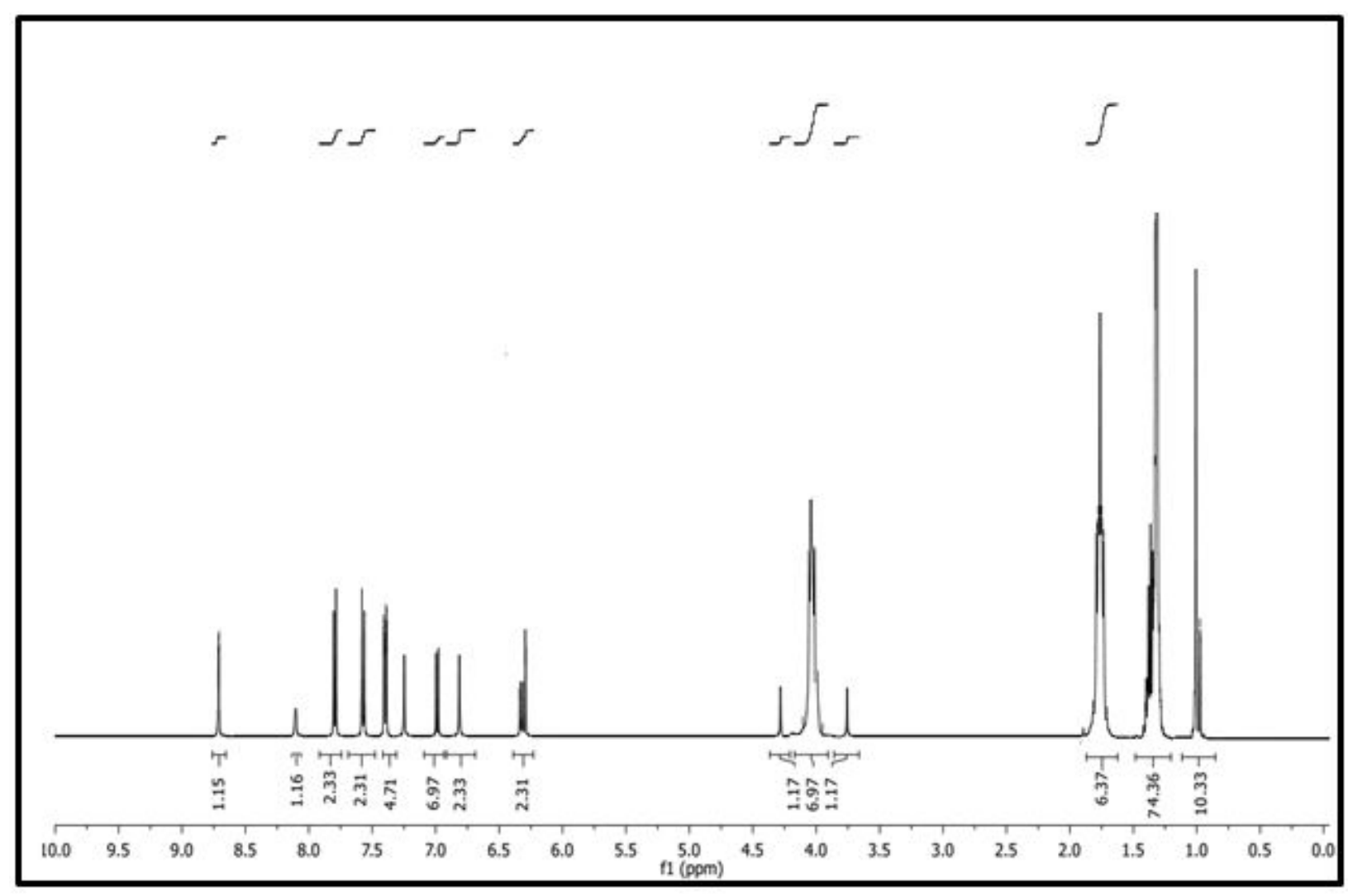

Figure S42. ${ }^{1} \mathrm{H}$ NMR of compound 10c 


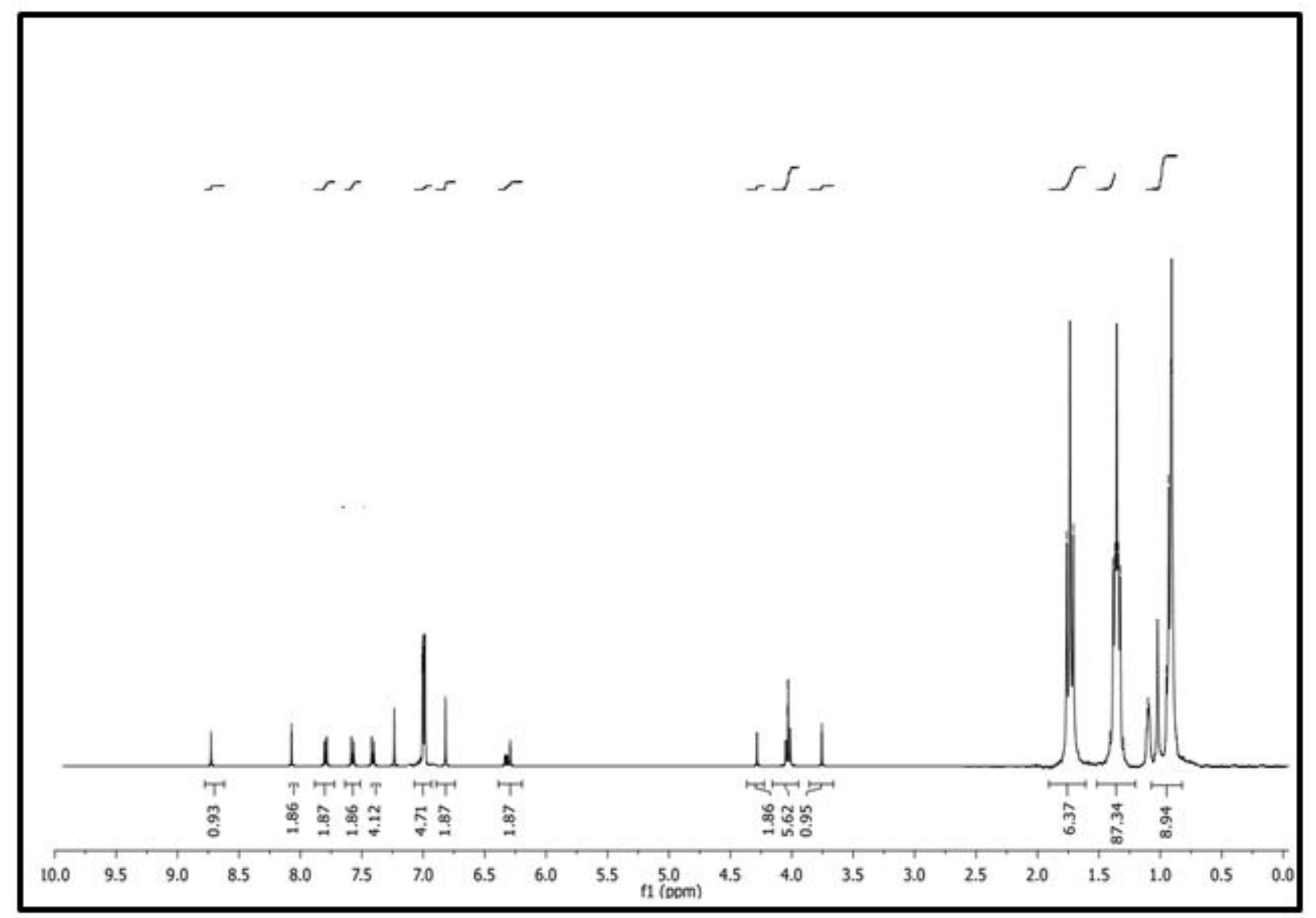

Figure S43. ${ }^{1} \mathrm{H}$ NMR of compound $\mathbf{1 0 d}$ 


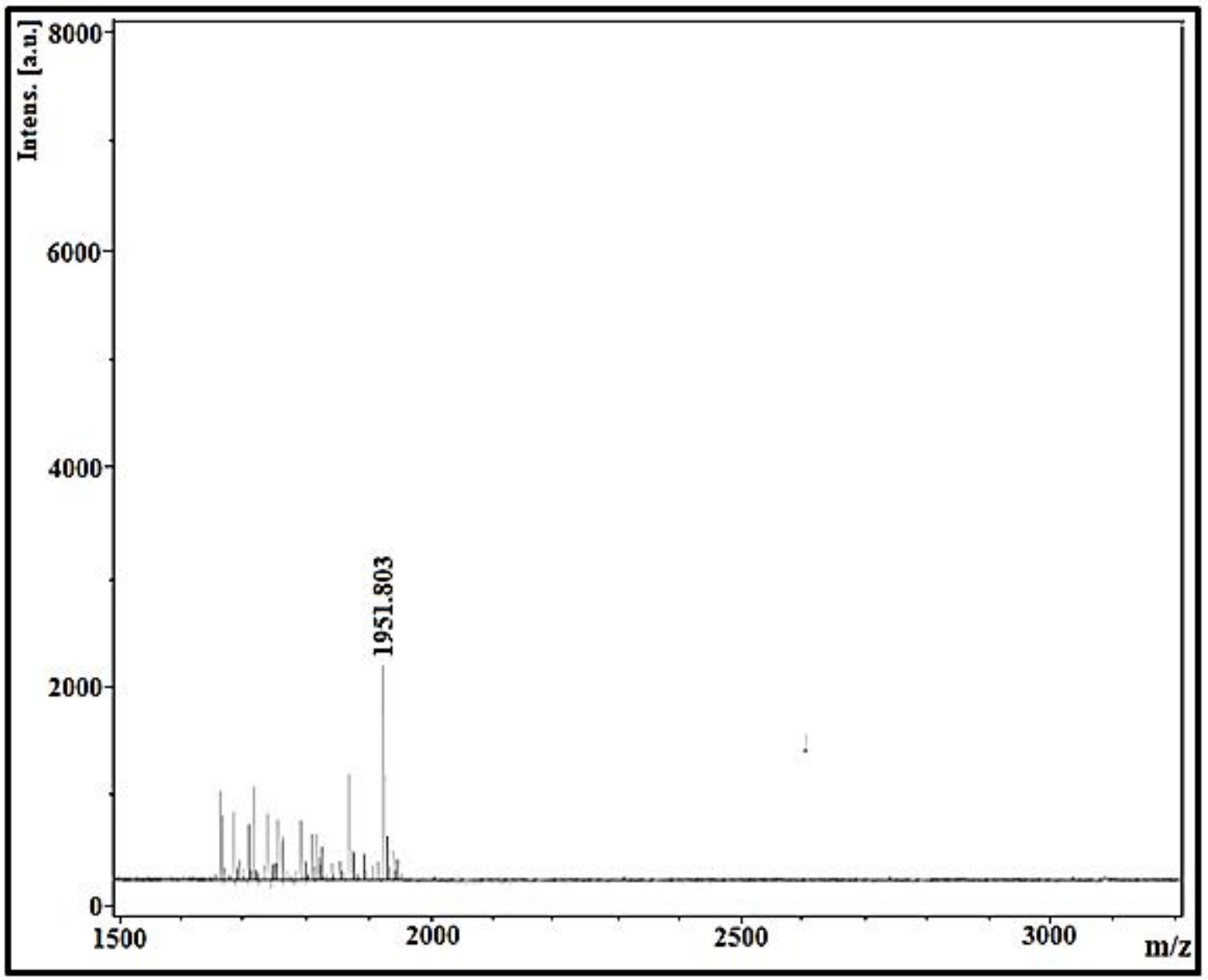

Figure S44. MALDI-TOF mass spectra of compound 10a 


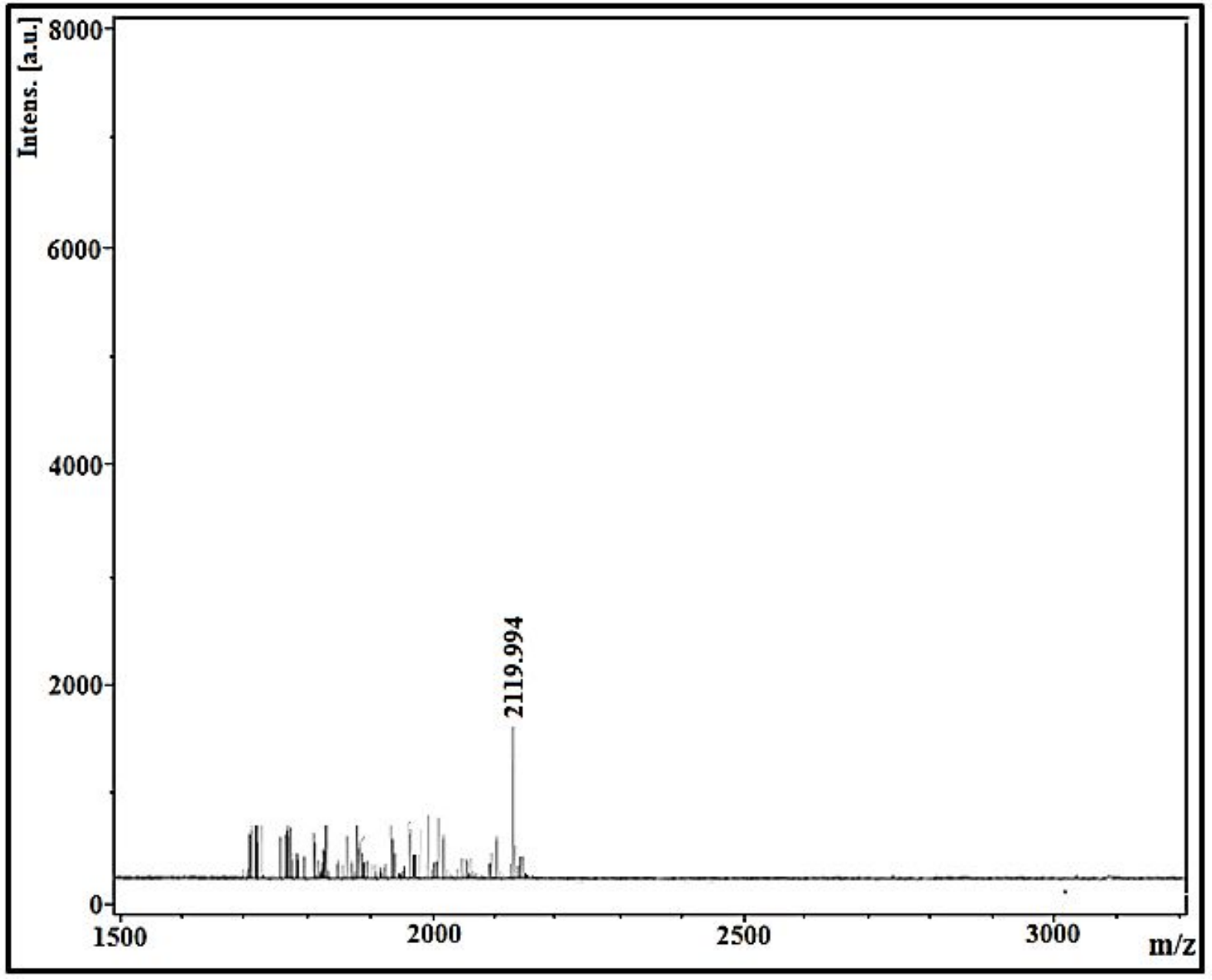

Figure S45. MALDI-TOF mass spectra of compound 10b 


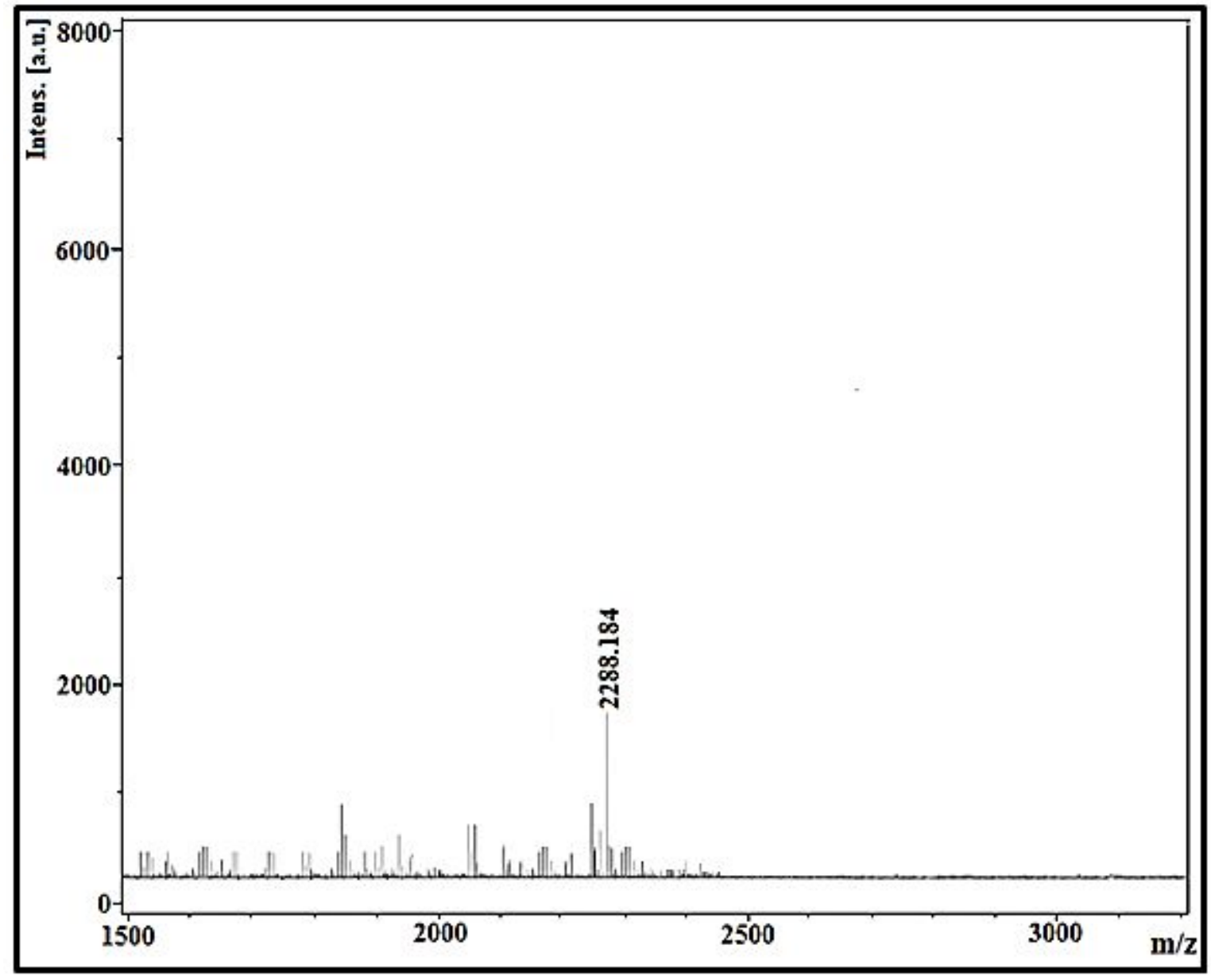

Figure S46. MALDI-TOF mass spectra of compound 10c 


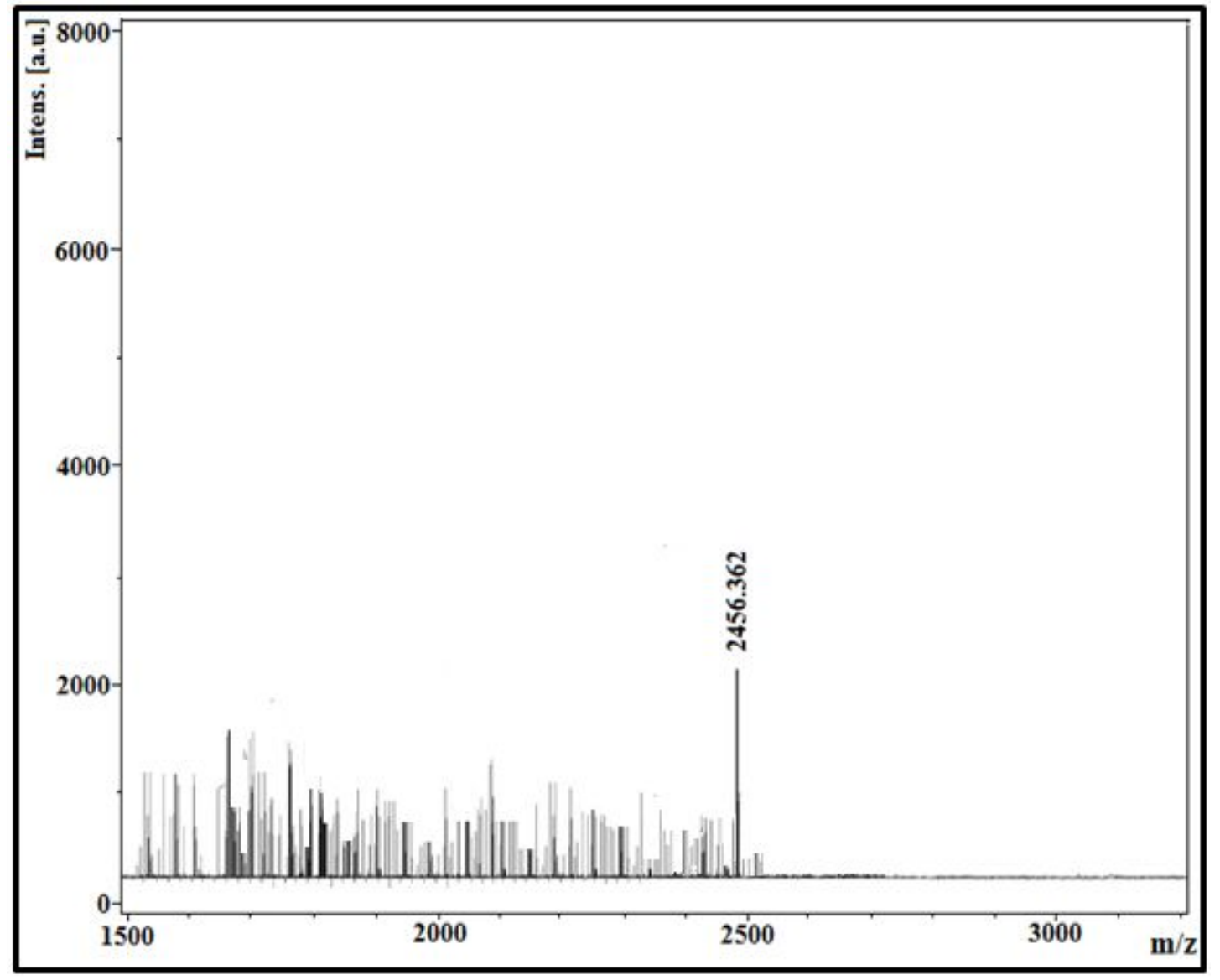

Figure S47. MALDI-TOF mass spectra of compound 10d 


\section{References}

1. Pathak, S.K.; Nath, S.; De, J.; Pal, S.K.; Achalkumar, A.S. Contrasting effects of heterocycle substitution and branched tails in the arms of star-shaped molecules. New J. Chem. 2017, 41, 4680-4688.

2. Tomi, I.H.R.; Al-Heatimi, D.T.A.; Jaffer, H.J. Asymmetric 1,3,4-thiadiazole derivatives: Synthesis, characterization and studying their liquid crystalline properties. Journal of Molecular Structure. 2017, 1141, 176-185.

3. Sharma, V.S.; Patel, R.B. The effect of position of tert-butyl tail group on the formation of liquid crystal in Schiff base ester based homologous series. Mol.Cryst.Liq.Cryst. 2017, 643, 53-65.

4. Kumagai, H.; Hasegawa, M.; Miyanari, S.; Sugawa, Y.; Sato, Y.; Hori,T.; Ueda, S.;

Kamiyama, H.; Miyano, S. Facile Synthesis of p-tert-butyl thiacalix[4]arene by the reaction of p-tert-butyl phenol with elemental sulphur in the presence of base. Tetrahedron Letters. 1997, 38, 3971-3972.

5. Sharma, V.S.; Sharma, A.S.; Vekariya, R.H. Columnar self-assembly of bowl-shaped luminescent oxadiazole calix[4]arene derivatives. Journal of Molecular Liquids. 2018, 271, 319-327. 